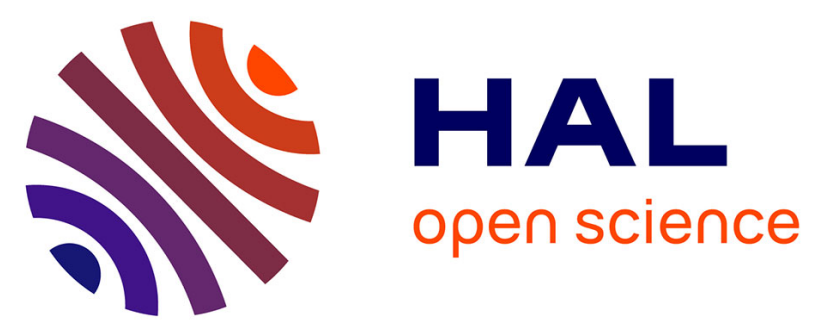

\title{
Retrieving LAI, chlorophyll and nitrogen contents in sugar beet crops from multi-angular optical remote sensing: Comparison of vegetation indices and PROSAIL inversion for field phenotyping
} Sylvain Jay, Fabienne Maupas, Ryad Bendoula, Nathalie Gorretta

\section{To cite this version:}

Sylvain Jay, Fabienne Maupas, Ryad Bendoula, Nathalie Gorretta. Retrieving LAI, chlorophyll and nitrogen contents in sugar beet crops from multi-angular optical remote sensing: Comparison of vegetation indices and PROSAIL inversion for field phenotyping. Field Crops Research, 2017, 210, pp.33-46. 10.1016/j.fcr.2017.05.005 . hal-01730271

\section{HAL Id: hal-01730271 \\ https://hal.science/hal-01730271}

Submitted on 13 Mar 2018

HAL is a multi-disciplinary open access archive for the deposit and dissemination of scientific research documents, whether they are published or not. The documents may come from teaching and research institutions in France or abroad, or from public or private research centers.
L'archive ouverte pluridisciplinaire HAL, est destinée au dépôt et à la diffusion de documents scientifiques de niveau recherche, publiés ou non, émanant des établissements d'enseignement et de recherche français ou étrangers, des laboratoires publics ou privés. 


\section{Retrieving LAI, chlorophyll and nitrogen contents in sugar beet crops from multi-angular optical remote sensing: comparison of vegetation indices and PROSAIL inversion for field phenotyping}

Sylvain Jay ${ }^{a, b, *}$, Fabienne Maupas $^{c}$, Ryad Bendoula $^{a}$, Nathalie Gorretta ${ }^{a}$

a Irstea, UMR ITAP, 361 rue J.F. Breton, 34196 Montpellier, France

${ }^{b}$ Aix Marseille Univ, CNRS, Centrale Marseille, Institut Fresnel, F-13013 Marseille, France

${ }^{c}$ Institut Technique de la Betterave, 45 rue de Naples, 75008 Paris, France

\section{Abstract}

Remote sensing has gained much attention for agronomic applications such as crop management or yield estimation. Crop phenotyping under field conditions has recently become another important application that requires specific needs: the considered remote-sensing method must be (1) as accurate as possible so that slight differences in phenotype can be detected and related to genotype, and (2) robust so that thousands of cultivars potentially quite different in terms of plant architecture can be characterized with a similar accuracy over different years and soil and weather conditions. In this study, the potential of nadir and off-nadir ground-based spectro-radiometric measurements to remotely sense five plant traits relevant for field phenotyping, namely, the leaf area index (LAI), leaf chlorophyll and nitrogen contents, and canopy chlorophyll and nitrogen contents, was evaluated over fourteen sugar beet (Beta vulgaris L.) cultivars, two years and three study sites. Among the diversity of existing remote-sensing methods, two popular approaches based on various selected Vegetation Indices (VI) and PROSAIL inversion were compared, especially in the perspective of using them for phenotyping applications.

Overall, both approaches are promising to remotely estimate LAI and canopy chlorophyll content $(R M S E \leq 10 \%)$. In addition, VIs show a great potential to retrieve canopy nitrogen content $(R M S E=$ $10 \%)$. On the other hand, the estimation of leaf-level quantities is less accurate, the best accuracy being obtained for leaf chlorophyll content estimation based on VIs $(R M S E=17 \%)$. As expected 
when observing the relationship between leaf chlorophyll and nitrogen contents, poor correlations are found between VIs and mass-based or area-based leaf nitrogen content. Importantly, the estimation accuracy is strongly dependent on sun-sensor geometry, the structural and biochemical plant traits being generally better estimated based on nadir and off-nadir observations, respectively.

Ultimately, a preliminary comparison tends to indicate that, providing that enough samples are included in the calibration set, (1) VIs provide slightly more accurate performances than PROSAIL inversion, (2) VIs and PROSAIL inversion do not show significant differences in robustness across the different cultivars and years. Even if more data are still necessary to draw definitive conclusions, the results obtained with VIs are promising in the perspective of high-throughput phenotyping using UAVembedded multispectral cameras, with which only a few wavebands are available.

Keywords: Chlorophyll and nitrogen contents, Field phenotyping, Leaf area index, Multi-angular optical remote sensing, Sugar beet.

\section{Introduction}

Over the last few years, sugar beet (Beta vulgaris L.) has received much attention for either sugar or biofuel productions. It is a credible alternative to sugarcane and therefore, increasing the crop yield by creating new cultivars, e.g., requiring less nitrogen fertilization, or having a better light use efficiency, is currently investigated. However, cultivar selection requires a deep understanding of how the plant genetic makeup (genotype) relates to the observable plant traits (phenotypes), and how the genes express themselves in a given environment (Furbank and Tester, 2011). Significant advances in genomics and gene technology have been done in the past decades, thus making in-field highthroughput phenotyping one of the major bottlenecks in plant breeding (Comar et al., 2012; Furbank and Tester, 2011; Montes et al., 2007). As phenotypes must be characterized over time, nondestructive techniques have to be developed. In this context, using optical remote sensing has proven to be powerful to accurately estimate plant traits describing the canopy structure, e.g., plant height, 
green fraction, leaf area index (LAI), and the leaf biochemistry, e.g., chlorophyll and nitrogen contents (Comar et al., 2012; Jay et al., 2015; Thorp et al., 2015). An accurate retrieval of such structural and biochemical parameters is critical for plant phenotyping. For example, chlorophyll content was recently suggested to be positively correlated to sugar beet yield, as an increase in chlorophyll content may result in a higher photosynthetic assimilation and a greater production of biomass (Loel et al., 2014). Also, as nitrogen is one of the most important limiting key nutrients, it is essential to better understand how genotypes differ in the use of nitrogen sources so as to optimize nitrogen fertilization. Indeed, besides being harmful to the environment, an excessive fertilization leads to an overproduction of leaves, which does not increase significantly radiation interception. Furthermore, sugar accumulation is inversely related to nitrogen uptake (Werker et al., 1999). On the other hand, nitrogen deficiency affects leaf expansion (Milford et al., 1985), thus decreasing photosynthetic assimilation and crop yield. Therefore, a compromise has to be reached. To our knowledge, the potential of optical remote sensing for field phenotyping of sugar beet plant traits has not been explored yet, and is investigated in this study.

Multi-angular optical observations offer a great potential to achieve the required accuracy for the remote sensing of structural and biochemical crop properties for field phenotyping. Indeed, the incoming radiation in the optical domain strongly interacts with vegetation through absorption and scattering processes both at the leaf scale (Jacquemoud and Baret 1990) and the canopy scale (Verhoef, 1984), the reflected radiation thus containing valuable information about the scene of interest. Furthermore, the use of several viewing configurations (independently or jointly) can potentially improve the retrieval accuracy when compared to using a single nadir observation (Dorigo 2012; Duan et al. 2014; Hilker et al. 2011; Song et al. 2016; Yang et al. 2011) since the sun-sensor geometry may strongly affect the canopy reflectance sensitivity to the targeted parameter(s) (Jacquemoud et al. 2009). In fact, the anisotropy of canopy reflectance closely relates to the physical properties and geometrical arrangement of vegetation elements (Widlowski et al., 2004). Multiangular measurements thus provide complementary sources of information to characterize the 
structure and biochemistry of crop canopies in a more robust and accurate way, especially if these canopies have a complex 3D structure and intermediate density (Dorigo, 2012). As a result, exploring the anisotropy of the reflectance of row-structured sugar beet canopies seems promising to obtain a high estimation accuracy as required for cultivar selection and other agronomic applications, e.g., crop management or yield prediction.

Numerous methods have been developed to extract canopy properties from (mono- or multi-angular) remotely sensed spectral data (Baret and Buis 2008; Dorigo et al. 2007; Verrelst et al. 2015). Statistical approaches based on vegetation indices (VIs) are very popular due to their simplicity, robustness and accuracy in retrieving targeted variables. These Vls have been designed in such a way that features of interest are enhanced while undesired effects are minimized. The high spectral resolution provided by current sensors allows computing narrow-band VIs that can detect subtle changes in reflectance, e.g., the red-edge position that relates to both the LAI and leaf chlorophyll content (Cho and Skidmore 2006; Clevers and Kooistra 2012; Guyot and Baret 1988). These VIs can be used to estimate either structural properties such as LAI (Darvishzadeh et al., 2011; Haboudane et al., 2004) and green fraction (Comar et al., 2012), or biochemical properties such as leaf chlorophyll content (Zarco-Tejada et al. 2004) and leaf water content (Colombo et al., 2008). However, interactions between biochemical and structural canopy parameters (e.g., LAl and leaf chlorophyll content) may add some uncertainties in the retrieval, the measured signal not only depending on the leaf biochemistry but also on the amount of leaves within the sensor field of view (Baret et al. 2007; Colombo et al. 2008). Alternatively, canopy integrated biochemical parameters (obtained by multiplying the leaf biochemical content by the LAI) can generally be estimated more accurately (Clevers and Kooistra 2012; Colombo et al. 2008; Darvishzadeh et al. 2011; Jacquemoud et al. 1995), while still representing physically-sound quantities (Baret et al. 2007). Interestingly, the correlation between chlorophyll and nitrogen contents makes it possible to use chlorophyll VIs for quantifying the nitrogen status of crops (Clevers and Gitelson 2013; Clevers and Kooistra 2012; Schlemmer et al. 2013). However, differences occur between different crops: while Xu et al. (2014), He, Song, et al. (2016) and He, Zhang, et al. (2016) have reported strong correlations 
between VIs and leaf nitrogen content in winter wheat and barley, poor correlations were obtained by Li et al. (2016) in litchi orchards. This suggests that further studies are necessary to evaluate the potential of VI-based remote sensing to retrieve nitrogen content in sugar beet cultivars.

The use of such statistically-based methods may, however, be not fully optimal for phenotyping applications, since the latter necessitates robust remote-sensing methods that can adapt to potentially strongly different plant architectures and characterize thousands of cultivars with a similar accuracy (the huge amount of tested cultivars obviating the possibility of including all of them in the calibration data set). Alternatively, inverting radiative transfer models may appear as a more robust approach to characterize different sugar beet canopies. These physically-based models simulate light propagation within the canopy as a function of leaf and soil properties, canopy structure and sun-sensor geometry. Whenever possible, model inversion allows for the retrieval of targeted variables based on iterative optimization, look-up tables, statistically-based methods or machine learning algorithms (Baret and Buis 2008), and provides a valuable physical understanding of interactions occurring between light and vegetation. PROSAIL (Baret et al. 1992; Jacquemoud et al. 2009) is one of the most widely used models, especially because it offers a good compromise between realism and simplicity (Verger et al., 2014) and because it is freely available to the community. PROSAIL simulates the canopy reflectance by combining the PROSPECT (Leaf Optical Properties Spectra) model of leaf optical properties (Jacquemoud and Baret 1990) and the SAIL (Scattering by Arbitrarily Inclined Leaves) canopy reflectance model (Verhoef 1984; Verhoef 1985). Importantly, SAIL has been designed for homogeneous canopies, so it is theoretically not well suited for modeling discontinuous crop rows. A number of studies have, however, shown that reasonable estimations of leaf and canopy chlorophyll contents and LAI could be achieved for such vegetation arrangements (Dorigo 2012; Duan et al. 2014; Jacquemoud et al. 1995).

In this study, we compare two popular remote-sensing approaches, i.e., VIs and PROSAIL inversion, based on their abilities to remotely sense the LAI as well as the leaf and canopy chlorophyll contents 
in sugar beet crops under field conditions. In addition, the potential of VIs for retrieving leaf and canopy nitrogen contents is investigated. Special attention is paid to the potential of the above two approaches in providing accurate and robust performances, as necessary for phenotyping applications. The considered spectral measurements are ground-based, which allows higher spatial and temporal resolutions as compared with satellite or aircraft measurements. A high revisit frequency is particularly attractive for agronomic and phenotyping applications because crop characterization may be required over a short critical period (Inoue et al., 2012).

\section{Materials and methods}

\subsection{Field experiments}

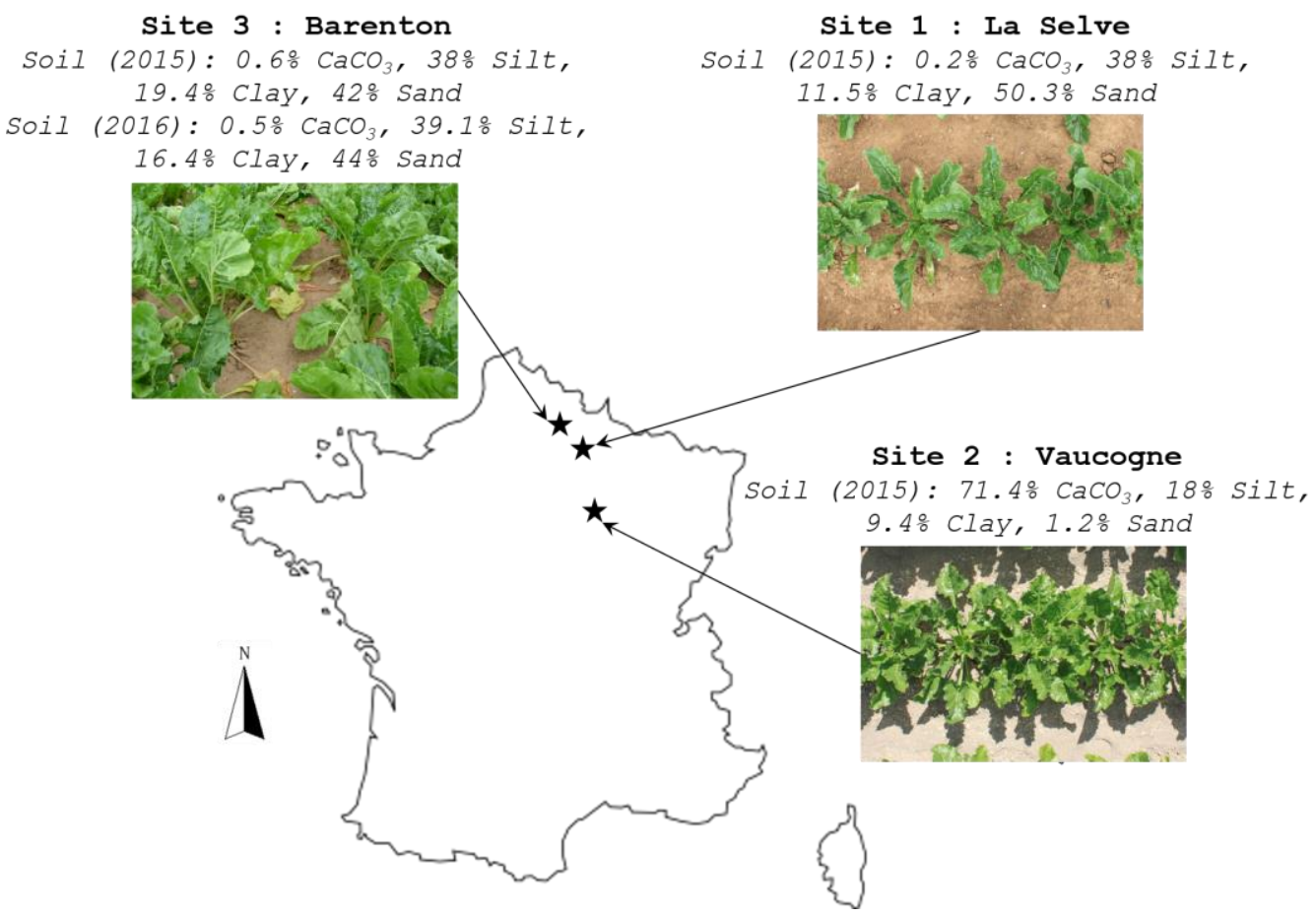

Figure 1: Locations of the three study sites and soil compositions (loamy soils for sites 1 and 3, and chalky soil for site 2). Photographs illustrate some of the sugar beet canopies encountered in each site.

Field experiments were conducted in France during the 2015 and 2016 growing seasons. Three study sites with different soil properties were considered (Fig. 1). The "La Selve" $\left(49^{\circ} 35^{\prime} \mathrm{N}, 4^{\circ} 01^{\prime} \mathrm{E}\right.$, denoted site 1) and "Barenton" $\left(49^{\circ} 37^{\prime} \mathrm{N}, 3^{\circ} 39^{\prime} \mathrm{E}\right.$, denoted site 3) sites were characterized by different loamy 
soils, whereas the "Vaucogne" site $\left(48^{\circ} 31^{\prime} \mathrm{N}, 4^{\circ} 21^{\prime} \mathrm{E}\right.$, denoted site 2$)$ was characterized by a chalky soil. Row spacing was $0.45 \mathrm{~m}$ for each experiment, and rows were oriented according to a $220^{\circ}$ azimuth for sites 1 and 2 (with respect to the North direction), and to a $190^{\circ}$ azimuth for site 3 . The characteristics of field experiments are further detailed in Table 1. Each experiment was a randomized complete block design using a factorial arrangement of various nitrogen fertilizations and/or cultivars with 3 replicates. Overall, 8 levels of fertilization and 14 cultivars exhibiting differences in structure were considered (note that cultivars No. 4 to 12 were only considered on 07/08/2015). In total, our data set contained 71 samples and thus encompassed a large variability due to differences in years, cultivars, nitrogen fertilizations, development stages and soil and weather conditions.

Table 1: Characteristics of field experiments. $\Theta_{s}$ and $\varphi_{s}$ are, respectively, the sun zenith and azimuth angles at the time of measurements.

\begin{tabular}{cccccccc}
\hline Date & Site & $\theta_{s}\left(^{\circ}\right)$ & $\varphi_{s}\left(^{\circ}\right)$ & Illumination & $\begin{array}{c}\text { Cultivar } \\
\text { No. }\end{array}$ & $\begin{array}{c}\text { Number of } \\
\text { samples }\end{array}$ & $\begin{array}{c}\text { Nitrogen rate } \\
\text { (kg N/ha) }\end{array}$ \\
\hline $06 / 23 / 2015$ & 1 & 28 & 190 & Partly cloudy & $1-3$ & 9 & $0,130,170$ \\
$06 / 24 / 2015$ & 2 & 29 & 155 & Clear & $1-3$ & 8 & $0,70,110$ \\
$06 / 30 / 2015$ & 1 & 30 & 218 & Clear & $1-2$ & 2 & 0 \\
$07 / 08 / 2015$ & 3 & 28 & 201 & Cloudy & $2,4-12$ & 10 & 80 \\
$07 / 21 / 2015$ & 1 & 35 & 137 & Cloudy & $1-2$ & 3 & 0,130 \\
$08 / 04 / 2015$ & 1 & 32 & 182 & Partly cloudy & $1-2$ & 4 & 0,130 \\
$09 / 08 / 2015$ & 1 & 44 & 200 & Cloudy & $1-3$ & 5 & $0,130,170$ \\
$05 / 24 / 2016$ & 3 & 30 & 199 & Clear & $2-3,13-14$ & 6 & $0,100,150$ \\
$06 / 06 / 2016$ & 3 & 34 & 227 & Cloudy & $2-3,13-14$ & 6 & $0,100,150$ \\
$06 / 21 / 2016$ & 3 & 32 & 137 & Cloudy & $2-3,13-14$ & 6 & $0,100,150$ \\
$07 / 05 / 2016$ & 3 & 34 & 133 & Clear & $2-3,13-14$ & 6 & $0,100,150$ \\
$07 / 19 / 2016$ & 3 & 49 & 107 & Clear & $2-3,13-14$ & 6 & $0,100,150$ \\
\hline
\end{tabular}

\subsection{Reflectance measurements}

Each sample represented a $0.45 \mathrm{~m}^{2}$ row-structured subplot containing five successive sugar beet plants. Each subplot was considered for both reflectance and reference measurements. Spectral 
measurements were carried out over the $350-2500 \mathrm{~nm}$ region using a FieldSpec 4 spectroradiometer (ASD Inc., Boulder, CO, USA), whose spectral sampling (resp., spectral resolution) was $1.4 \mathrm{~nm}$ (resp., 3 $\mathrm{nm}$ ) in the visible and near infrared range and $1.1 \mathrm{~nm}$ (resp., $10 \mathrm{~nm}$ ) in the short-wave infrared range. The spectral data were collected around solar noon, with a sun zenith angle generally lower than $35^{\circ}$. The difference in azimuth between the solar and row directions ranged from 0 to $85^{\circ}$. The illumination

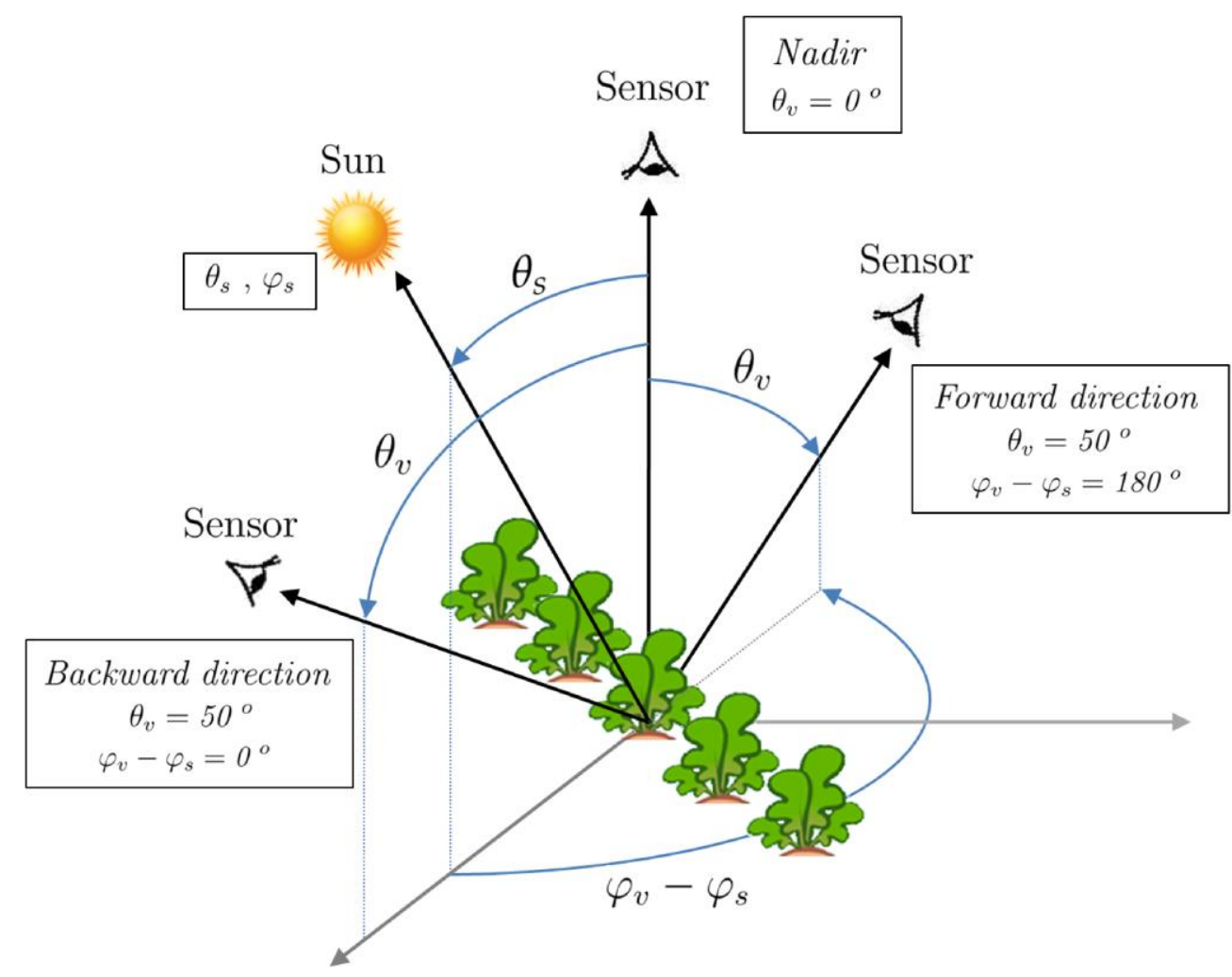

Figure 2: Sun-sensor geometry for the three viewing configurations. $\theta_{\mathrm{s}}$ and $\Theta_{\mathrm{v}}$ are, respectively, the sun and viewing zenith angles, while $\varphi_{\mathrm{s}}$ and $\varphi_{\mathrm{v}}$ are, respectively, the sun and viewing azimuth angles.

conditions strongly differed between experiments, ranging from a clear blue sky to an overcast sky (Table 1). As represented in Fig. 2, for each sample, the reflected radiation was measured $1.50 \mathrm{~m}$ away from the middle plant of the subplot (in order to avoid edge effects) in nadir and off-nadir directions. For nadir measurements, the spectroradiometer fiber optic was hold manually, pointing vertically downward. The off-nadir measurements were performed by holding the fiber optic with a probe stand positioned such that the reflected radiation was measured at a $50^{\circ}$ viewing zenith angle in both the backward and forward scattering directions (i.e., respectively, viewing azimuth angles of 0 and $180^{\circ}$ 
relatively to the sun azimuth angle). Note that in the following, the backward and forward configurations are denoted $-50^{\circ}$ and $+50^{\circ}$, respectively. Taking a $50^{\circ}$ viewing zenith angle ensured us to be far enough from the hot-spot for every spectral acquisition. For both nadir and off-nadir measurements, the pointing accuracy was assumed to be sufficient for not affecting the estimation results. The instrument field of view was $25^{\circ}$, resulting in a measured circular area of $67 \mathrm{~cm}$ diameter at nadir. Each radiance spectrum was obtained from the average of 50 readings, and converted into a hemispherical-conical reflectance factor (Schaepman-Strub et al. 2006) (subsequently referred to as reflectance) using a Spectralon ${ }^{\circledR}$ white reference panel. Finally, atmospheric absorption bands ranging from 1340 to $1500 \mathrm{~nm}$, and from 1790 to $2100 \mathrm{~nm}$ were removed before further processing.

\subsection{Reference measurements}

After spectral acquisition, the leaf angle distribution was estimated based on leaf angle measurements (one for each plant, 180 in total). Leaf angle was retrieved applying basic trigonometry to the rightangle triangle delimited by the leaf and its projection onto the soil surface.

Subsequently, non-destructive measurements of leaf chlorophyll content $\left(C_{a b}\right.$, in $\left.\left[\mu \mathrm{g} / \mathrm{cm}^{2}\right]\right)$ were performed over the five considered plants (six measurements per plant at different shoot levels so as to take into account for the $\mathrm{C}_{\mathrm{ab}}$ vertical profile in leaves of different age or different location in the canopy, i.e., thirty $\mathrm{C}_{\mathrm{ab}}$ measurements in total) using a Dualex scientifict ${ }^{\mathrm{TM}}$ (Force-A, Orsay, France). This leafclip enables transmittance-based $C_{a b}$ measurements characterized by an initial accuracy of around $5 \mu \mathrm{g} / \mathrm{cm}^{2}$ (Cerovic et al., 2012). As observed in previous studies (Cerovic et al., 2012; Jay et al., 2016), the Dualex tends to underestimate $C_{a b}$ for high content values in dicotyledons. Sensor readings were therefore converted to actual $C_{a b}$ values using the relationship proposed by Cerovic et al. (2012) for dicotyledons, thus achieving an estimated accuracy of around $4 \mu \mathrm{g} / \mathrm{cm}^{2}$. The thirty $C_{a b}$ values were finally averaged so as to provide a single $C_{a b}$ value for each subplot.

Two methods were used for LAI measurements. In 2015, each subplot was harvested to measure leaf area. Leaves were placed on blank sheets and flattened with a pane of glass. They were then scanned 
and after extraction of leaf-related pixels by image processing, their area was estimated using the calibrated pixel size. The LAI was finally obtained by multiplying the leaf area averaged over the five plants by the plant density (from 10 to 12 plants per square meter for the three sites). In 2016, LAI was non-destructively measured based on hemispherical photographs acquired early in the morning (to minimize the influence of direct sunlight) with a digital camera positioned above the canopy. LAl was estimated from these photographs using the CAN-EYE freeware (http://www6.paca.inra.fr/can-eye/). Importantly, $\mathrm{C}_{\mathrm{ab}}$ and LAI were poorly correlated $\left(R^{2}=0.14\right)$, thus preventing from obtaining spurious statistical relationships between VIs and $C_{a b}$ inherited from a more causal relationship between VIs and LAI.

Leaves were then weighted and placed in a drying oven at $75^{\circ} \mathrm{C}$ for $48 \mathrm{~h}$. Their dry mass was measured so as to retrieve the equivalent water thickness $\left(C_{w}\right.$, in $\left.[\mathrm{cm}]\right)$ and leaf mass per area $\left(C_{m}\right.$, in $\left.\left[\mathrm{g} / \mathrm{cm}^{2}\right]\right)$ according to $C_{w}=\frac{F W-D W}{L A} \times d_{w}$ and $C_{m}=\frac{D W}{L A}$, where $F W$ and $D W$ are, respectively, the fresh and dry weights of leaves, $L A$ is the leaf area, and $d_{w}=1 \mathrm{~g} / \mathrm{cm}^{3}$ is the water density. In addition, the dry mass per unit soil area $\left(\mathrm{W}_{\text {leaf, }}\right.$ in $\left.\left[\mathrm{g} / \mathrm{m}^{2}\right]\right)$ was calculated by multiplying the dry mass averaged over the five plants by the plant density.

The average leaf nitrogen concentration (\% $\mathrm{N}_{\text {leaf, }}$ in [\%] of dry mass) of the whole subplot was measured using the Dumas method (Dumas, 1831). The leaf nitrogen content $\left(C_{n}\right.$, in $\left.\left[\mu \mathrm{g} / \mathrm{cm}^{2}\right]\right)$ was obtained by the ratio of $\% \mathrm{~N}_{\text {leaf }}$ to the specific leaf area (i.e., the ratio of leaf area to dry mass). The total canopy chlorophyll content (CCC) was approximated by the product of $\mathrm{LAI}$ and $\mathrm{C}_{\mathrm{ab}}$ as defined by Jacquemoud et al. (1995) and Baret et al. (2007) (note that this approximation neglects the chlorophyll contained in other elements than leaves such as stems), whereas the canopy nitrogen content (CNC) was given by the product of $\% \mathrm{~N}_{\text {leaf }}$ and $\mathrm{W}_{\text {leaf }}$ (Baret et al. 2007).

Table 2: Statistics of leaf-level and canopy-level reference measurements.

\begin{tabular}{|c|c|c|c|c|}
\hline Parameter & Unit & Min / Max & Mean & $\begin{array}{l}\text { Standard } \\
\text { deviation }\end{array}$ \\
\hline
\end{tabular}




\begin{tabular}{cccccc}
\hline & Leaf angle & $\circ$ & $24 / 80$ & 55 & 11 \\
& $C_{a b}$ & $\mu g / \mathrm{cm}^{2}$ & $27.1 / 58.4$ & 40.8 & 9.0 \\
Leaf level & $\mathrm{C}_{\mathrm{w}}$ & $\mathrm{cm}$ & $0.0380 / 0.0816$ & 0.0538 & 0.0094 \\
& $\mathrm{C}_{\mathrm{m}}$ & $\mathrm{g} / \mathrm{cm}^{2}$ & $0.0058 / 0.0118$ & 0.0084 & 0.0015 \\
& $\% \mathrm{~N}_{\text {leaf }}$ & $\%$ & $2.26 / 4.61$ & 3.42 & 0.58 \\
& $\mathrm{C}_{\mathrm{n}}$ & $\mu \mathrm{g} / \mathrm{cm}^{2}$ & $202 / 381$ & 280 & 43 \\
\hline \multirow{3}{*}{ Canopy level } & $\mathrm{LAl}$ & $\mathrm{m}^{2} / \mathrm{m}^{2}$ & $0.28 / 3.25$ & 1.72 & 0.71 \\
& $\mathrm{~W}_{\text {leaf }}$ & $\mathrm{g} / \mathrm{m}^{2}$ & $19 / 289$ & 144 & 65 \\
& $\mathrm{CCC}$ & $\mathrm{g} / \mathrm{m}^{2}$ & $0.09 / 1.64$ & 0.72 & 0.39 \\
& $\mathrm{CNC}$ & $\mathrm{g} / \mathrm{m}^{2}$ & $0.77 / 9.54$ & 4.83 & 2.33 \\
\hline
\end{tabular}

An overview of these reference measurements is shown in Table 2. Note that, for more clarity in notation, leaf chlorophyll and nitrogen contents were expressed in $\left[\mu \mathrm{g} / \mathrm{cm}^{2}\right]$ (micrograms per unit leaf area) whereas canopy chlorophyll and nitrogen contents were expressed in $\left[\mathrm{g} / \mathrm{m}^{2}\right]$ (grams per unit soil area).

\subsection{Remote-sensing methods}

\subsubsection{Vegetation index based approach}

A number of chlorophyll or LAI VIs were selected from the literature based on their potential to retrieve LAI, leaf and canopy chlorophyll and nitrogen contents from canopy spectral measurements (Table 3). Simple ratios and normalized difference ratios have widely been used for $\mathrm{C}_{\mathrm{ab}}$ estimation at the leaf and canopy levels. These two-band indices consist in combining a band that is sensitive to both absorption by chlorophyll and scattering by leaf, and a normalization band that is only sensitive to scattering, e.g., a near-infrared (NIR) band (Blackburn, 2007). This enables absorption and scattering to be separated so as to capture mainly variations in $\mathrm{C}_{\mathrm{ab}}$. The Normalized Difference Vegetation Index (NDVI) (Rouse et al., 1973) is an example of such VIs, and was tested in this study due to its popularity in the remotesensing and agronomic communities as a vegetation indicator. Still, it is known that bands located quite far from chlorophyll absorption peaks (e.g., in the green and red-edge domains) are to be preferred in 
order to avoid saturation and maximize the sensitivity to $C_{a b}$ (Gitelson et al. 1996; Gitelson and Merzlyak 1994; Sims and Gamon 2002). Two VIs based on simple ratios, i.e., $C I_{\text {green }}$ and $C I_{\text {red-edge }}$ (Gitelson et al. 2006; Gitelson et al. 2005; Gitelson et al. 2003) and two other normalized difference ratios, i.e., $N D_{550}$ (Gitelson et al., 1996) and $N D_{705}$ (Gitelson and Merzlyak, 1994) were therefore chosen in this study, as they were found to be accurate predictors of $C_{a b}$ at the leaf level (Gitelson et al., 2006, 2003, 1996; Gitelson and Merzlyak, 1994; Schlemmer et al., 2013) and canopy chlorophyll content at the canopy level (Clevers and Gitelson 2013; Clevers and Kooistra 2012; Gitelson et al. 2005; Schlemmer et al. 2013) in crops such as maize, soybean or potato.

We also tested two VIs proposed by Wu et al. (2008) and derived from the Modified Chlorophyll Absorption Ratio Index (MCARI) (Daughtry et al., 2000). The first one is MCARI [705,750], where bands 670 and $800 \mathrm{~nm}$ in MCARI have been replaced by bands 705 and $750 \mathrm{~nm}$ so as to mitigate saturation occurring for high LAI and/or $C_{a b}$ values. Even if MCARI was originally designed for $C_{a b}$ estimation, several studies have shown that MCARI-derived VIs (including MCARI[705,750]) also hold a great potential for LAI prediction (Comar et al., 2012; Daughtry et al., 2000; Haboudane et al., 2004; Wu et al., 2008). The other VI modified by $\mathrm{Wu}$ et al. (2008) and selected in this study is MCARI/ OSAVI $[705,750]$ that have been derived from MCARI/OSAVI (Daughtry et al., 2000), the OSAVI (Optimized Soil-Adjusted Vegetation Index) index (Rondeaux et al. 1996) being introduced to lessen the background influence for low LAI values.

Off-nadir measurements are less affected by the soil influence than nadir measurements. It thus seems appropriate to use VIs that minimize the variations in leaf reflectance observed at this scale, e.g., those caused by leaf orientation and specular reflection. Ratios of reflectance difference such as the Modified Red-edge Ratio (mSR) (Sims and Gamon, 2002) and MERIS Terrestrial Chlorophyll Index (MTCI) (Dash and Curran, 2004) decrease the two above influences, as such effects can, respectively, be approximated by multiplicative and additive perturbations under the bi-directional hypothesis in the visible domain (Jay et al., 2016). The $m N D_{\text {blue }}$ recently proposed by Jay et al. (2017) using millimeter- 
to centimeter-scale imagery of sugar beet canopies was also included in this study because it has proven to offer a strong sensitivity to $C_{a b}$ when the soil influence is low.

Finally, the Angular Insensitivity Vegetation Index (AIVI) recently developed by He, Song, et al. (2016) for leaf nitrogen content estimation in winter wheat was tested to see whether it was also obtaining strong correlations in sugar beet canopies.

These eleven VIs were computed for the three viewing angles and compared based on their linear correlation (in terms of Pearson's correlation coefficient, $r$ ) with $\mathrm{C}_{\mathrm{ab}}, \mathrm{LAl}, \mathrm{CCC}, \% \mathrm{~N}_{\text {leaf }}, \mathrm{C}_{\mathrm{n}}$ and CNC. For the best cases, linear regressions were performed over the whole data set, and root mean square errors of prediction (RMSE) were estimated using leave-one-out cross-validation due to the relatively low number of samples.

Table 3: Vegetation indices selected from the literature.

\begin{tabular}{|c|c|c|}
\hline Vegetation index & Formulation & References \\
\hline$N D V I$ & $\frac{R_{800}-R_{670}}{R_{800}+R_{670}}$ & Rouse et al. (1973) \\
\hline$C I_{\text {green }}$ & $\frac{R_{780}}{R_{550}}-1$ & Gitelson et al. $(2003,2005,2006)$ \\
\hline$C I_{\text {red-edge }}$ & $\frac{R_{780}}{R_{710}}-1$ & Gitelson et al. $(2003,2005,2006)$ \\
\hline$N D_{550}$ & $\frac{R_{750}-R_{550}}{R_{750}+R_{550}}$ & Gitelson et al. (1996) \\
\hline$N D_{705}$ & $\frac{R_{750}-R_{705}}{R_{750}+R_{705}}$ & Gitelson and Merzlyak (1994) \\
\hline$M C A R I[705,750]$ & {$\left[\left(R_{750}-R_{705}\right)-0.2\left(R_{750}-R_{550}\right)\right]\left(R_{750} / R_{705}\right)$} & Wu et al. (2008) \\
\hline MCARI/OSAVI $[705,750]$ & $\frac{\left[\left(R_{750}-R_{705}\right)-0.2\left(R_{750}-R_{550}\right)\right]\left(R_{750} / R_{705}\right)}{1.16\left(R_{750}-R_{705}\right) /\left(R_{750}+R_{705}+0.16\right)}$ & Wu et al. (2008) \\
\hline$m S R$ & $\frac{R_{750}-R_{445}}{R_{705}-R_{445}}$ & Sims and Gamon (2002) \\
\hline MTCI & $\frac{R_{754}-R_{709}}{R_{709}-R_{681}}$ & Dash and Curran (2004) \\
\hline$m N D_{\text {blue }}$ & $\frac{R_{440}-R_{728}}{R_{440}+R_{850}}$ & Jay et al. (2017) \\
\hline$A I V I$ & $\frac{R_{445}\left(R_{720}+R_{735}\right)-R_{573}\left(R_{720}-R_{735}\right)}{R_{720}\left(R_{573}+R_{445}\right)}$ & He, Song, et al. (2016) \\
\hline
\end{tabular}

\subsubsection{PROSAIL based approach}


The $\mathrm{C}_{\mathrm{ab}}$, LAI and CCC parameters were also estimated based on PROSAIL inversion (note that nitrogen contents could not be retrieved since leaf nitrogen content is not a PROSAIL input parameter). In this study, we implemented the PRO4SAIL model (available at http://teledetection.ipgp.jussieu.fr/prosail/) that combines PROSPECT 5b (Feret et al., 2008) and 4SAIL (Verhoef et al. 2007). PROSPECT 5b simulates the leaf directional hemispherical reflectance and transmittance from 400 to $2500 \mathrm{~nm}$ as a function of leaf biochemistry and internal structure. PROSPECT $5 \mathrm{~b}$ parameters are the leaf structure parameter $\mathrm{N}$ (unitless), chlorophyll $\mathrm{a}+\mathrm{b}$ content $\mathrm{C}_{\mathrm{ab}}\left(\right.$ in $\left[\mu \mathrm{g} / \mathrm{cm}^{2}\right]$ ), carotenoid content $\mathrm{C}_{\mathrm{cx}}$ (in $\left[\mu \mathrm{g} / \mathrm{cm}^{2}\right]$ ), brown pigment content $C_{b p}$ (unitless), equivalent water thickness $C_{w}$ (in [cm]) and leaf mass per area $C_{m}$ (in $\left.\left[\mathrm{g} / \mathrm{cm}^{2}\right]\right)$.

4SAIL is a numerically robust and speed-optimized version of the SAIL model (Verhoef 1984; Verhoef 1985), which has been modified to include the hot-spot effect (Kuusk 1991; Verhoef 1998). SAIL simulates the bidirectional reflectance (and other reflectance quantities derived from the bidirectional case) of a homogeneous vegetation canopy for a given sun-sensor geometry determined by the sun zenith angle $\left(\Theta_{\mathrm{s}}\right.$, in $\left.^{\circ}\right)$, the viewing zenith angle $\left(\theta_{\mathrm{v}}\right.$, in $\left.^{\circ}\right)$ and the relative viewing azimuth angle $\left(\varphi_{\mathrm{sv}}=\varphi_{\mathrm{v}^{-}}\right.$ $\varphi_{s}$, in $\left.{ }^{\circ}\right)$. In 4SAIL, the canopy structure is described using the LAI $\left(\right.$ in $\left.\left[\mathrm{m}^{2} / \mathrm{m}^{2}\right]\right)$, the leaf inclination distribution function (unitless), the hot-spot parameter (unitless) and the soil brightness (unitless). In addition, the fraction of diffuse illumination (unitless) allows for considering the sky influence and was used to model the measured reflectance following the procedure proposed by François et al. (2002). PRO4SAIL (simply referred to as PROSAIL hereafter) was inverted for each viewing angle independently based on the widely used Look-Up Table (LUT) approach (Baret and Buis 2008; Darvishzadeh et al. 2011; Dorigo 2012; Duan et al. 2014; Verger et al. 2014; Verrelst et al. 2015; Vohland et al. 2010). This consists in (1) generating a synthetic data set from multiple runs of the canopy reflectance model based on different sets of input variables, and (2) calculating the solution of the inverse problem based on the LUT entries whose simulated spectra are the closest to the measured one. This approach is widely used as compared to, e.g., numerical optimization or artificial neural networks, especially because of 
its abilities to avoid local minima and to introduce constraints on the retrieved variables, its simplicity and its computational efficiency once the LUT has been built. Incidentally, note that numerical optimization was also tested but actually performed poorer than the LUT approach (not shown).

Before the LUT generation, several model parameters were set to default values or values derived from prior or expert knowledge in order to reduce the ill-posedness of the inversion problem (Combal et al., 2003). $C_{b p}$ was set to zero since no senescent leaves were visible during the field experiments. As suggested by Jacquemoud et al. (1995) for sugar beet, the leaf inclination distribution function was assumed to be ellipsoidal and characterized by an Average Leaf Angle (ALA, in ${ }^{\circ}$ ), and the hot-spot parameter was set to 0.33 . The soil was assumed to be Lambertian and, for each date, the soil brightness was fixed based on a soil reflectance spectrum acquired at nadir. As a result, only 7 unknown parameters ( $N, C_{a b}, C_{c x}, C_{w}, C_{m}, L A l$ and ALA) were used to generate the LUT.

For this purpose, uniform distributions were first used for every unknown parameter (no prior knowledge was thus introduced in model inversion). These distributions were bounded by the minimum and maximum values presented in Table 4 and determined according to the literature (Darvishzadeh et al. 2011; Dorigo 2012; Duan et al. 2014; Jacquemoud et al. 1995; Verger et al. 2014) and the reference measurements displayed in Table 2.

Table 4: Variation ranges of the unknown PROSAIL parameters used for generating the LUT.

\begin{tabular}{cccccccc}
\hline Parameter & $\mathrm{N}$ & $\mathrm{C}_{\mathrm{ab}}$ & $\mathrm{C}_{\mathrm{cx}}$ & $\mathrm{C}_{\mathrm{w}}$ & $\mathrm{C}_{\mathrm{m}}$ & LAl & $\mathrm{ALA}$ \\
\hline Minimum value & 1 & 20 & 5 & 0.03 & 0.002 & 0.1 & 10 \\
Maximum value & 2 & 65 & 20 & 0.09 & 0.015 & 3.5 & 90
\end{tabular}

A full orthogonal experimental design (Bacour et al., 2002; Verger et al., 2014) was used to conveniently combine these 7 parameters by (1) subdividing each variation range into 4 equidistant intervals (or classes), (2) sampling every combination of classes once (resulting in $4^{7}=16,384$ combinations), and (3) for each combination, randomly drawing every parameter value according to 
its specific distribution (which is uniform in this case). This allows populating more evenly the whole parameter space while limiting the number of simulations. For each of the 16,384 combinations of input parameters, the canopy reflectance was simulated between 400 and $2500 \mathrm{~nm}$ with a $1 \mathrm{~nm}$ spectral sampling interval, and the resulting spectrum was subsampled according the spectral resolution of the spectroradiometer (Section 2.2). A LUT was generated for each date and sun-sensor geometry, setting $\theta_{s}, \theta_{v}, \varphi_{s v}$ and the soil reflectance to their measured values. This resulted in 36 LUTs, corresponding to 12 dates and 3 sun-sensor geometries.

In order to further decrease the problem ill-posednes and improve the estimation of targeted parameters (i.e., LAI and $\mathrm{C}_{\mathrm{ab}}$ ) especially by limiting possible compensations between them (Baret and Buis, 2008), we also utilized prior knowledge on their distributions to generate a second set of 36 LUTs. For both parameters, we used Gaussian distributions with means and standard deviations obtained from reference measurements (Table 2), similarly to Verger et al. (2014). This allows each LUT to have more entries corresponding to the most frequently observed LAI and $\mathrm{C}_{\mathrm{ab}}$ values. In the following, model inversion using such Gaussian distributions is called constrained inversion, while model inversion using only uniform distributions is called unconstrained inversion.

To find the solution to the inverse problem, the root mean square error between the measured and simulated canopy reflectance spectra was computed for the $k^{\text {th }}$ LUT entry according to

$$
R M S E_{\theta_{v}, k}=\sum_{\lambda}\left(R_{\theta_{v}}(\lambda)-\hat{R}_{\theta_{v}, k}(\lambda)\right)^{2}
$$

where $R_{\theta_{v}}(\lambda)$ and $\hat{R}_{\theta_{v}, k}(\lambda)$ are, respectively, the measured and simulated spectra at wavelength $\lambda$ for the sun-sensor geometry denoted $\theta_{v}$ for the sake of simplicity. Following Darvishzadeh et al. (2011), the 10 LUT entries corresponding to the 10 smallest $R M S E_{\theta_{v}, k}$ values were considered as possible solutions and averaged so as to finally provide a unique solution to the inverse problem.

In addition, PROSAIL was also inverted using the three viewing angles simultaneously. Indeed, when the canopy reflectance model reliably describes the reflectance anisotropy, using various observations 
of the same scene potentially allows for constraining the inversion problem and increasing the retrieval accuracy. In this case, Eq. 1 was summed over the three sun-sensor geometries, resulting in the following cost function (Dorigo, 2012):

$$
R M S E_{k}=\sum_{\theta_{v}} R M S E_{\theta_{v}, k}=\sum_{\theta_{v}}\left[\sum_{\lambda}\left(R_{\theta_{v}}(\lambda)-\hat{R}_{\theta_{v}, k}(\lambda)\right)^{2}\right]
$$

Similarly to mono-angular observations, the 10 best LUT entries were then averaged to provide the estimated parameters.

\subsubsection{Preliminary comparison of approaches for phenotyping applications}

Besides comparing the above two remote-sensing methods based on their abilities to estimate biochemical and structural properties of sugar beet crops, we also studied how these methods were performing over different cultivars and years in the perspective of phenotyping. For both approaches, the RMSE per cultivar and per year was therefore evaluated in order to detect possible varietal and year differences. Note that the comparison only included the variables that could be estimated with both approaches, i.e. $\mathrm{C}_{\mathrm{ab}}$, LAI and CCC. In the case of VIs, each cultivar (resp., year) was considered once for validation using the model calibrated with the other cultivars (resp., the other year). This allowed us to assess whether a statistical model could be applied to unknown cultivars or other years with the same accuracy, as required for phenotyping applications.

For both methods, variations in performance were quantified computing the weighted standard deviation of RMSE (denoted $\sigma$ ) over cultivars and years. Weighting factors were defined as the numbers of samples per cultivar (resp., per year) in order to take into account the strong discrepancies in the number of samples per cultivar (resp., per year). In such a preliminary study where the relatively low number of samples prevented us from drawing any definitive conclusion, the $\sigma$ variable appears as a relevant indicator to compare the two approaches for phenotyping purpose.

\section{Results}




\subsection{Relationships between chlorophyll and nitrogen quantities}
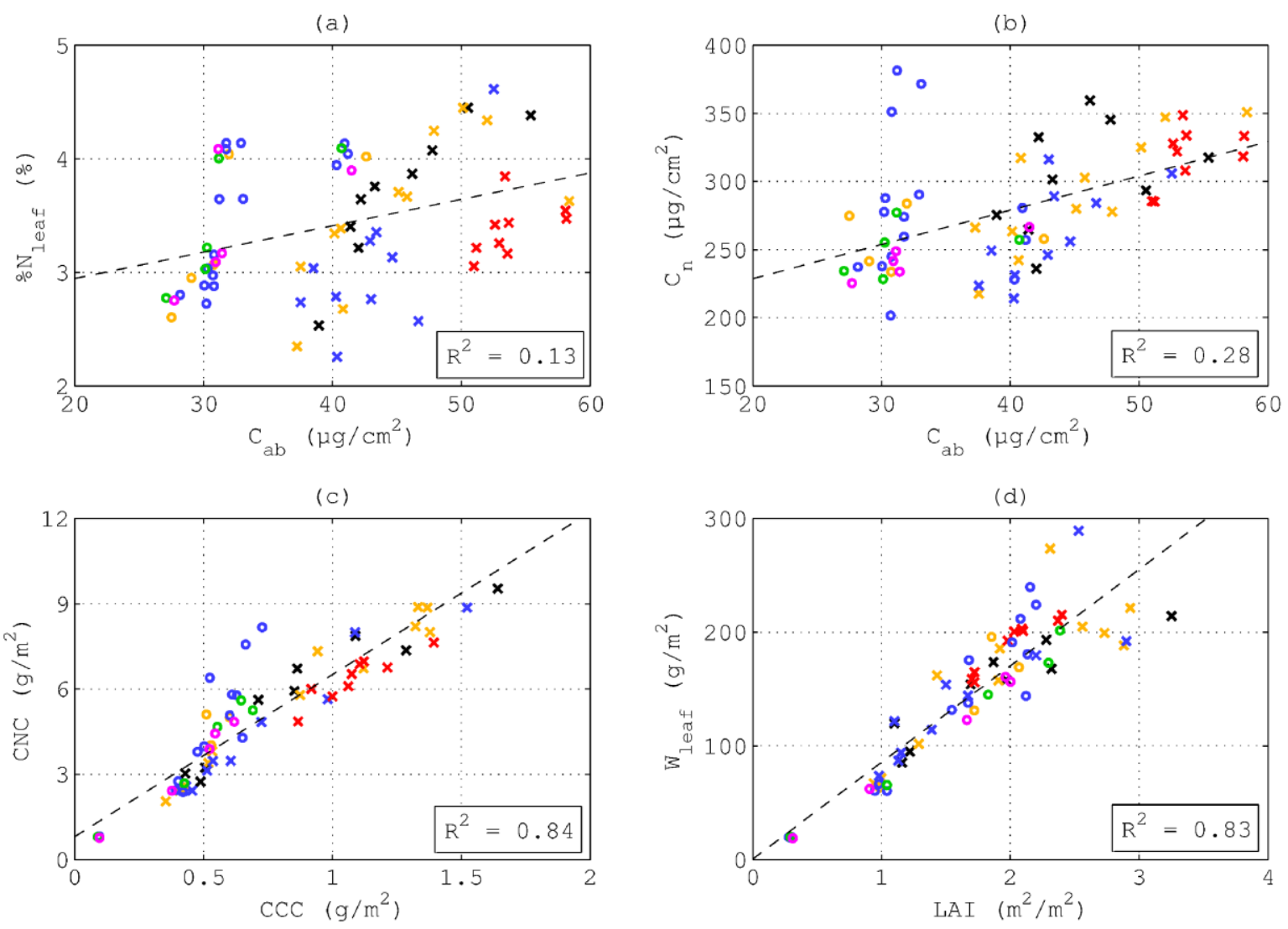

Figure 3: Relationships between chlorophyll and nitrogen quantities at the leaf (a-b) and canopy (c) levels, and between LAI and biomass per unit area (d). Cultivars No. 1, 2, 3, 13 and 14 are in dark, orange, blue, green and magenta, resp., while cultivars No. 4 to 12 are in red. Crosses and circles refer to 2015 and 2016 experiments, resp. The coefficient of determination $\left(R^{2}\right)$ indicates the strength of each relationship.

In Fig. 3, preliminary results are presented to show how the chlorophyll and nitrogen quantities introduced in Section 2.3 correlate in sugar beet crops. In Fig. 3.a, the leaf nitrogen concentration \% $\mathrm{N}_{\text {leaf }}$ as measured using the reference method shows a very poor correlation $\left(R^{2}=0.13\right)$ with the leaf chlorophyll content $C_{a b}$ measured using the Dualex leafclip. As shown in Fig. 3.b, the chlorophyll/nitrogen correlation increases when converting $\% \mathrm{~N}_{\text {leaf }}$ to leaf nitrogen content $\mathrm{C}_{n}$, yielding a $R^{2}$ of 0.28 . This correlation is, however, markedly lower than that obtained between the canopy integrated quantities CNC and CCC (Fig. 3.C), i.e., $R^{2}=0.84$. It is worth noting that the latter strong 
correlation is not only due to the correlation between $\% \mathrm{~N}_{\text {leaf }}$ and $\mathrm{C}_{\mathrm{ab}}$, but also (and primarily) to the correlation between LAI and biomass per unit soil area as shown in Fig. 3.d.

\subsection{Estimation performances obtained using vegetation indices}

Table 5: Pearson's correlation coefficients $(r)$ obtained between vegetation indices and $\mathrm{C}_{\mathrm{ab}}$, LAI and CCC. For each column, the best performing index is in bold.

\begin{tabular}{|c|c|c|c|c|c|c|c|c|c|}
\hline \multirow{2}{*}{ Vegetation index } & \multicolumn{3}{|c|}{$0^{\circ}$} & \multicolumn{3}{|c|}{$-50^{\circ}$} & \multicolumn{3}{|c|}{$+50^{\circ}$} \\
\hline & $\mathrm{C}_{\mathrm{ab}}$ & LAI & $\mathrm{CCC}$ & $\mathrm{C}_{\mathrm{ab}}$ & LAI & $\mathrm{CCC}$ & $\mathrm{C}_{\mathrm{ab}}$ & LAI & $\mathrm{CCC}$ \\
\hline$N D V I$ & 0.24 & 0.84 & 0.67 & 0.34 & 0.79 & 0.67 & 0.27 & 0.80 & 0.64 \\
\hline$C I_{\text {green }}$ & 0.36 & 0.94 & 0.85 & 0.71 & 0.86 & 0.95 & 0.58 & 0.83 & 0.88 \\
\hline$C I_{\text {red-edge }}$ & 0.40 & 0.94 & 0.87 & 0.68 & 0.88 & 0.94 & 0.58 & 0.87 & 0.91 \\
\hline$N D_{550}$ & 0.35 & 0.92 & 0.79 & 0.60 & 0.86 & 0.86 & 0.51 & 0.86 & 0.83 \\
\hline$N D_{705}$ & 0.34 & 0.91 & 0.78 & 0.54 & 0.86 & 0.83 & 0.48 & 0.87 & 0.81 \\
\hline$M C A R I[705,750]$ & 0.45 & 0.94 & 0.90 & 0.63 & 0.89 & 0.93 & 0.58 & 0.93 & 0.95 \\
\hline MCARI/OSAVI $[705,750]$ & 0.47 & 0.95 & 0.90 & 0.60 & 0.90 & 0.92 & 0.57 & 0.93 & 0.93 \\
\hline$m S R$ & 0.42 & 0.93 & 0.87 & 0.68 & 0.87 & 0.94 & 0.61 & 0.86 & 0.92 \\
\hline$M T C I$ & 0.53 & 0.92 & 0.91 & 0.76 & 0.83 & 0.95 & 0.67 & 0.81 & 0.91 \\
\hline$m N D_{\text {blue }}$ & 0.62 & 0.59 & 0.77 & 0.82 & 0.47 & 0.77 & 0.73 & 0.44 & 0.70 \\
\hline AIVI & 0.59 & 0.88 & 0.91 & 0.79 & 0.79 & 0.94 & 0.76 & 0.72 & 0.88 \\
\hline
\end{tabular}

In Table 5, we compare the linear correlations obtained between $\mathrm{C}_{\mathrm{ab}}$, LAI and CCC, and the VIs presented in Table 3 and computed for the three viewing angles. At nadir, poor correlations $(r \leq 0.62)$ with $\mathrm{C}_{\mathrm{ab}}$ are obtained for all VIs. Conversely, LAI is strongly correlated $(r \geq 0.84)$ with every selected $\mathrm{VI}$ except $m N D_{\text {blue }}$, the best correlation being obtained using the MCARI-based and simple ratio VIs $(r \geq 0.94)$. These strong relationships with LAI generally result in good correlations with CCC, except for $N D V I$ and to a lesser extent $m N D_{\text {blue }}$, the $r$ values being higher than 0.90 for MCARI-based VIs, MTCI and AIVI. As compared with nadir viewing, significantly stronger correlations with $\mathrm{C}_{\mathrm{ab}}(0.54 \leq$ $r \leq 0.82$ ) are obtained in the $-50^{\circ}$ configuration for all tested VIs except $N D V I$, the best correlation being obtained with $m N D_{\text {blue }}$. Despite a lower sensitivity to LAl, the increased sensitivity to $\mathrm{C}_{\mathrm{ab}}$ generally leads to stronger correlations with CCC. The best performances are obtained using $C I_{\text {green }}$, 
$C I_{\text {red-edge }} m S R$ and $M T C I$ with $r \geq 0.94$. Correlations are generally lower at $+50^{\circ}$ than at $-50^{\circ}$. AIVI obtains the best correlation with $C_{a b}(r=0.76)$, while the two MCARI-based VIs perform significantly better than other VIs in estimating LAI $(r=0.93)$. As a result, these two latter VIs also obtain the best correlations with CCC $(r \geq 0.93)$.

Table 6: Pearson's correlation coefficients $(r)$ obtained between vegetation indices and the three nitrogen quantities \% $\mathrm{N}_{\text {leaf, }} \mathrm{C}_{\mathrm{n}}$ and $\mathrm{CNC}$. For each column, the best performing index is in bold.

\begin{tabular}{|c|c|c|c|c|c|c|c|c|c|}
\hline \multirow{2}{*}{ Vegetation index } & \multicolumn{3}{|c|}{$0^{\circ}$} & \multicolumn{3}{|c|}{$-50^{\circ}$} & \multicolumn{3}{|c|}{$+50^{\circ}$} \\
\hline & $\% \mathrm{~N}_{\text {leaf }}$ & $C_{n}$ & CNC & $\% \mathrm{~N}_{\text {leaf }}$ & $C_{n}$ & $\mathrm{CNC}$ & $\% N_{\text {leaf }}$ & $C_{n}$ & CNC \\
\hline$N D V I$ & -0.16 & 0.23 & 0.77 & -0.20 & 0.22 & 0.73 & -0.22 & 0.18 & 0.72 \\
\hline$C I_{\text {green }}$ & 0.11 & 0.35 & 0.90 & 0.23 & 0.48 & 0.88 & 0.24 & 0.42 & 0.84 \\
\hline$C I_{\text {red-edge }}$ & 0.13 & 0.36 & 0.90 & 0.19 & 0.46 & 0.89 & 0.22 & 0.43 & 0.88 \\
\hline$N D_{550}$ & -0.09 & 0.30 & 0.86 & 0.00 & 0.37 & 0.84 & -0.05 & 0.32 & 0.83 \\
\hline$N D_{705}$ & -0.06 & 0.29 & 0.85 & -0.03 & 0.34 & 0.83 & -0.05 & 0.31 & 0.83 \\
\hline$M C A R I[705,750]$ & 0.12 & 0.39 & 0.91 & 0.11 & 0.46 & 0.89 & 0.12 & 0.49 & 0.93 \\
\hline MCARI/OSAVI $[705,750]$ & 0.07 & 0.39 & 0.91 & 0.03 & 0.44 & 0.89 & 0.06 & 0.48 & 0.93 \\
\hline$m S R$ & 0.16 & 0.37 & 0.90 & 0.19 & 0.47 & 0.88 & 0.25 & 0.46 & 0.88 \\
\hline MTCI & 0.15 & 0.39 & 0.90 & 0.24 & 0.48 & 0.86 & 0.27 & 0.45 & 0.84 \\
\hline$m N D_{\text {blue }}$ & 0.44 & 0.53 & 0.66 & 0.48 & 0.61 & 0.58 & 0.46 & 0.55 & 0.54 \\
\hline AIVI & 0.21 & 0.45 & 0.89 & 0.23 & 0.53 & 0.84 & 0.31 & 0.51 & 0.78 \\
\hline
\end{tabular}

Similarly, in Table 6, we compare the linear correlations obtained between $\% \mathrm{~N}_{\text {leaf }}, \mathrm{C}_{\mathrm{n}}$ and $\mathrm{CNC}$, and the VIs presented in Table 3 and computed for the three viewing angles. On the one hand, poor relationships with leaf-level nitrogen quantities are obtained for the three viewing angles. VIs show no significant correlations with $\% \mathrm{~N}_{\text {leaf }}(r \leq 0.48)$. Slightly better correlations are obtained with $\mathrm{C}_{n}$, especially in the $-50^{\circ}$ configuration, the best performance being obtained using $m N D_{\text {blue }}$ with $r=0.61$. On the other hand, significant relationships with canopy nitrogen content CNC are generally obtained. For nadir viewing, CI green, $C I_{\text {red-edge }}, \quad M C A R I[705,750]$, MCARI/OSAVI[705,750], mSR, MTCI and AIVI perform similarly, MCARI [705,750] and MCARI/ OSAVI $[705,750]$ leading to the best correlations $(r=0.91)$. In the $-50^{\circ}$ configuration, the best 
performing VIs are $C I_{\text {red-edge }}, M C A R I[705,750]$ and MCARI/OSAVI[705,750] $(r=0.89)$, while in the $+50^{\circ}$ configuration, MCARI $[705,750]$ and $M C A R I / O S A V I[705,750]$ obtain significantly better correlations than other VIs $(r=0.93)$.
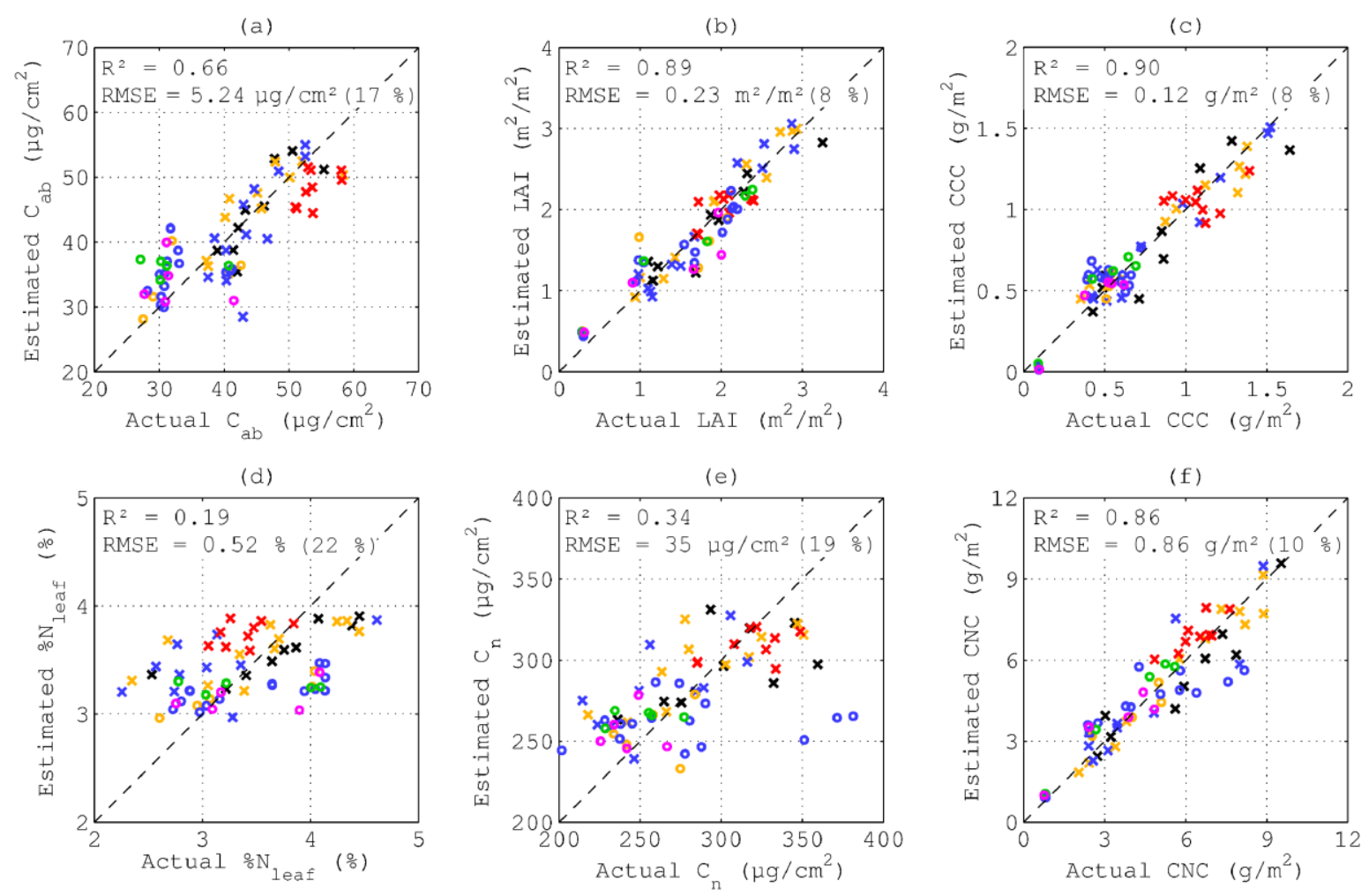

Figure 4: Best prediction performances obtained for (a) $\mathrm{C}_{\mathrm{ab}}\left(m N D_{\text {blue, }},-50^{\circ}\right)$, (b) LAI $(M C A R I /$ OSAVI $\left.[705,750], 0^{\circ}\right),\left(\right.$ c) CCC $\left(M T C I,-50^{\circ}\right)$, (d) $\% \mathrm{~N}_{\text {leaf }}\left(m N D_{\text {blue }},-50^{\circ}\right)$, (e) $\mathrm{C}_{\mathrm{n}}\left(m N D_{\text {blue }},-50^{\circ}\right)$, and (f) $\mathrm{CNC}$ $\left(M C A R I[705,750],+50^{\circ}\right)$. Cultivars and years are represented in a similar fashion as in Fig. 3 . The coefficient of determination $\left(R^{2}\right)$ and RMSEs are provided for each variable (relative RMSEs are indicated in parentheses).

In Fig. 4, we show the best prediction performances obtained for $\mathrm{C}_{a b}, \mathrm{LAl}, \mathrm{CCC}, \% \mathrm{~N}_{\text {leaf }}, \mathrm{C}_{n}$ and $\mathrm{CNC}$, based on the results presented in Table 5 and Table 6 . The different cultivars and years are clearly represented in order to notice any varietal and year effects, e.g., due to differences in canopy structure or nitrogen/chlorophyll relationship. The correlations observed in Table 5 and Table 6 between VIs and $\mathrm{C}_{\mathrm{ab}}$, LAI, CCC and CNC result in accurate predictions for these four parameters, obtaining RMSEs of $5.24 \mu \mathrm{g} / \mathrm{cm}^{2}$ (17 \% of $C_{a b}$ range), $0.23 \mathrm{~m}^{2} / \mathrm{m}^{2}(8 \%), 0.12 \mathrm{~g} / \mathrm{m}^{2}(8 \%)$ and $0.86 \mathrm{~g} / \mathrm{m}^{2}(10 \%)$, respectively. 
The estimations of $\% \mathrm{~N}_{\text {leaf }}$ and $\mathrm{C}_{\mathrm{n}}$ are less accurate, achieving RMSEs of $0.52 \%(22 \%)$ and $35 \mu \mathrm{g} / \mathrm{cm}^{2}$ (19\%), respectively.

\subsection{Estimation performances obtained based on PROSAIL inversion}
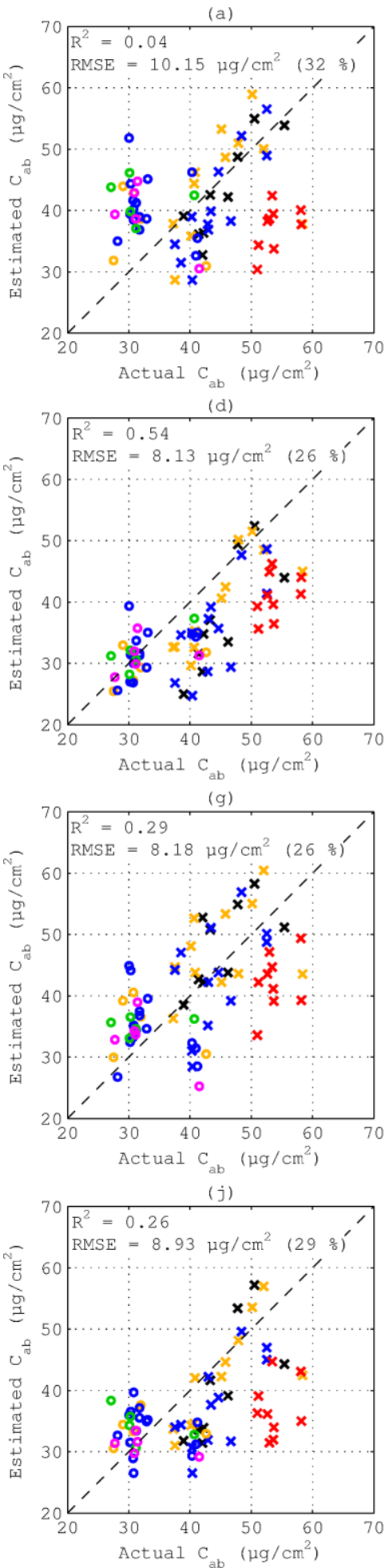
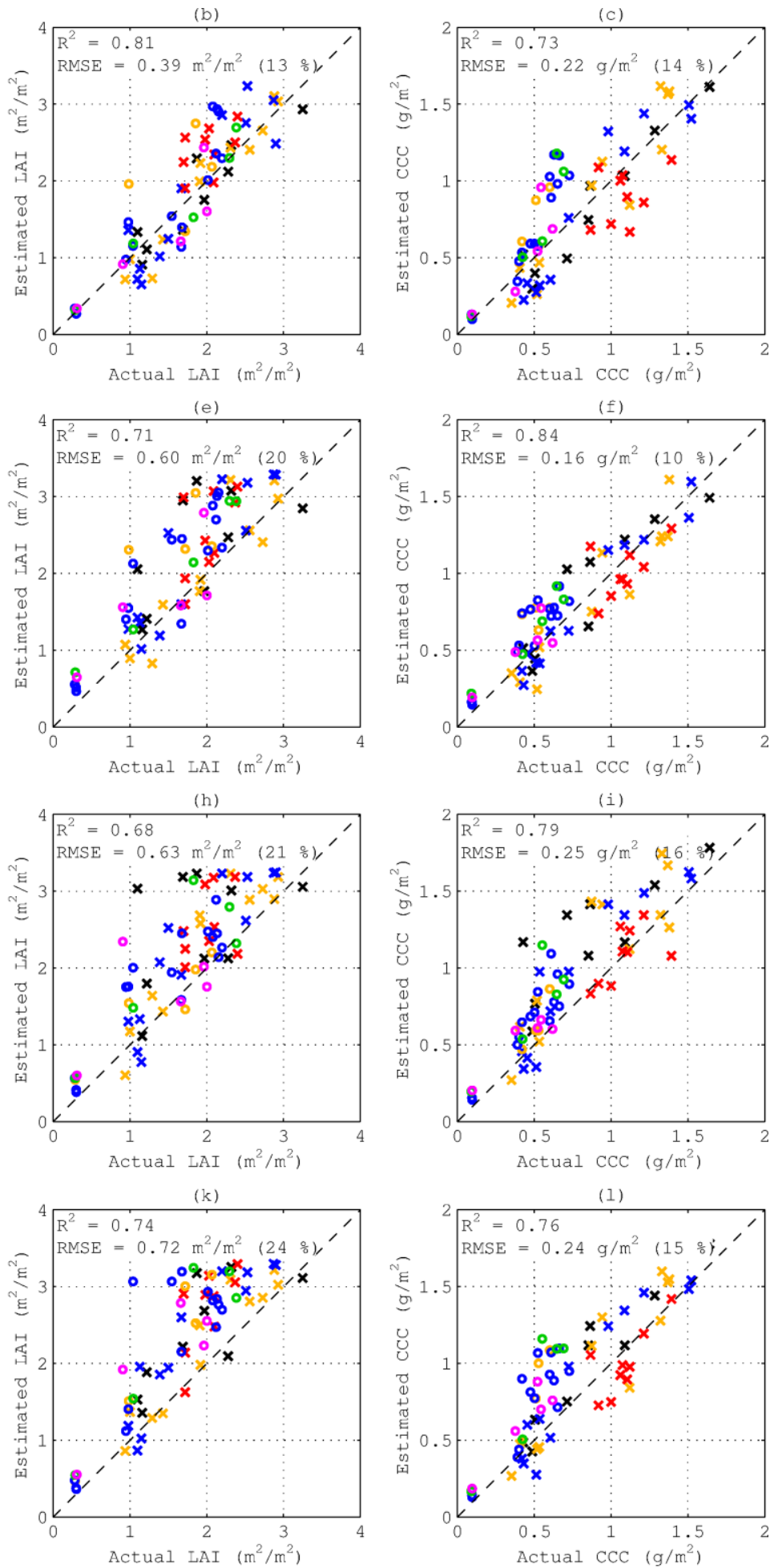
Figure 5: Estimation performances obtained based on unconstrained PROSAIL inversion for $\mathrm{C}_{\mathrm{ab}}$ (left-hand column), LAI (middle column) and CCC (right-hand column). Nadir observations are used for Figures (a-c), offnadir observations are used for Figures $(d-f)\left(-50^{\circ}\right)$ and $(g-i)\left(+50^{\circ}\right)$, and the three observations are used together for Figures (j-I). Cultivars and years are represented in a similar fashion as in Fig.3. The coefficient of determination $\left(\mathrm{R}^{2}\right)$ and RMSEs are provided for each variable/angle (relative RMSEs are indicated in parentheses).

In Fig. 5, we show the estimation results obtained with unconstrained PROSAIL inversion based on single-view $\left(0^{\circ},-50^{\circ}\right.$ and $+50^{\circ}$ independently $)$ and multiple-view $\left(0^{\circ},-50^{\circ}\right.$ and $+50^{\circ}$ together measurements. For nadir viewing (Fig. 5.a-c), $C_{a b}$ is poorly retrieved with a RMSE of $10.15 \mu \mathrm{g} / \mathrm{cm}^{2}(32 \%$ of $C_{a b}$ range). The $L A I$ retrieval is more accurate $\left(R M S E=0.39 \mathrm{~m}^{2} / \mathrm{m}^{2}, 13 \%\right)$, thus leading to a more accurate CCC retrieval as well (RMSE $\left.=0.22 \mathrm{~g} / \mathrm{m}^{2}, 14 \%\right)$. Somewhat different observations are made in the two off-nadir configurations. At $-50^{\circ}$ (Fig. 5.d-f), $C_{a b}$ is better estimated as compared with nadir $\left(R M S E=8.13 \mu \mathrm{g} / \mathrm{cm}^{2}, 26 \%\right)$, while the LAl retrieval accuracy decreases $\left(R M S E=0.60 \mathrm{~m}^{2} / \mathrm{m}^{2}, 20 \%\right)$ The overall $C_{a b}$ underestimation (Fig. 5.d) somewhat compensates for LAl overestimation (Fig. 5.e), which leads to a high CCC retrieval accuracy $\left(R M S E=0.16 \mathrm{~g} / \mathrm{m}^{2}, 10 \%\right)$. $\mathrm{C}_{\mathrm{ab}}$ and LAI are similarly retrieved at $+50^{\circ}$ as compared with $-50^{\circ}$ (Fig. 5.g-h), achieving RMSEs of $8.18 \mu \mathrm{g} / \mathrm{cm}^{2}(26 \%)$ and $0.63 \mathrm{~m}^{2} / \mathrm{m}^{2}(21 \%)$, respectively. However, fewer compensations between $\mathrm{C}_{\mathrm{ab}}$ and LAl occur as compared with the backward scattering direction, thus leading to lower CCC estimation performances, i.e., $R M S E=0.25 \mathrm{~g} / \mathrm{m}^{2}$ (16 \%) (Fig. 5.i). Using the three measurements simultaneously does not improve the above estimation results, respectively obtaining RMSEs of $8.93 \mu \mathrm{g} / \mathrm{cm}^{2}(29 \%), 0.72 \mathrm{~m}^{2} / \mathrm{m}^{2}$ (24\%) and $0.24 \mathrm{~g} / \mathrm{m}^{2}(15 \%)$ for $\mathrm{C}_{\mathrm{ab}}$, LAl and CCC. 

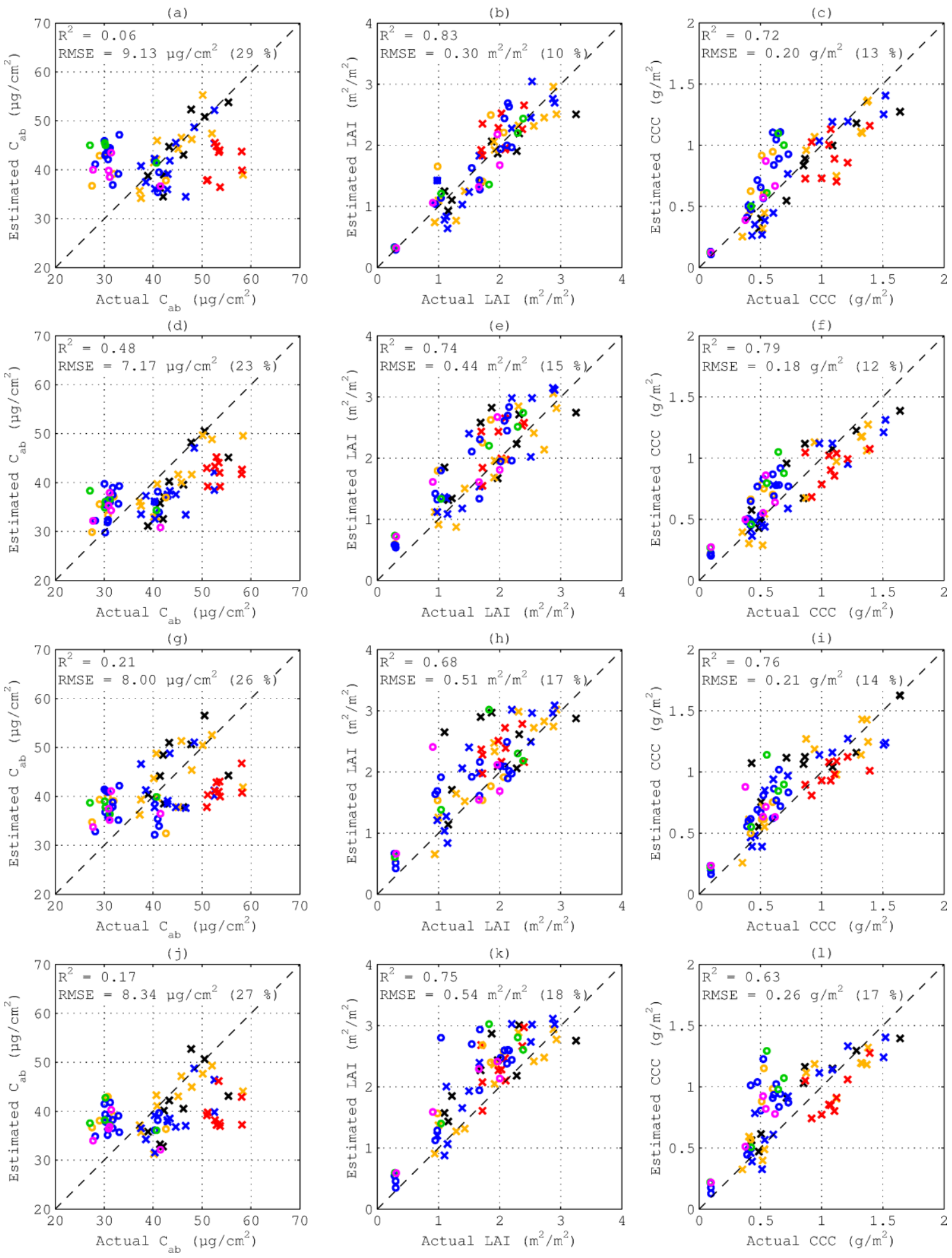

Figure 6: Estimation performances obtained based on constrained PROSAIL inversion for $\mathrm{C}_{\mathrm{ab}}$ (left-hand column), LAI (middle column) and CCC (right-hand column). Nadir observations are used for Figures (a-c), offnadir observations are used for Figures $(d-f)\left(-50^{\circ}\right)$ and $(g-i)\left(+50^{\circ}\right)$, and the three observations are used together for Figures (j-I). Cultivars and years are represented in a similar fashion as in Fig.3. The coefficient of 
determination $\left(\mathrm{R}^{2}\right)$ and RMSEs are provided for each variable/angle (relative RMSEs are indicated in parentheses).

Using prior knowledge on $\mathrm{C}_{\mathrm{ab}}$ and LAI distributions to constrain the LUT construction generally improves the estimation results (Fig. 6). For $\mathrm{C}_{\mathrm{ab}}$ and LAI, the RMSE decreases in every case, i.e., when using either single-view or multiple-view measurements. The best $C_{a b}$ retrieval performances are still achieved in the backward scattering direction (Fig. 6.d) with a RMSE of $7.17 \mu \mathrm{g} / \mathrm{cm}^{2}(23 \%$ ), while LAI is still better estimated from nadir viewing (Fig. 6.b), i.e., $R M S E=0.30 \mathrm{~m}^{2} / \mathrm{m}^{2},(10 \%)$. The benefit of using prior knowledge on $\mathrm{C}_{\mathrm{ab}}$ and LAI is less evident for CCC. Indeed, constrained PROSAIL inversion only improves the CCC retrieval accuracy at $0^{\circ}$ and $+50^{\circ}$, the best performances obtained at $-50^{\circ}$ (RMSE $=0.18 \mathrm{~g} / \mathrm{m}^{2}, 12 \%$, Fig. 6.f) being slightly inferior to those obtained with unconstrained PROSAIL inversion (Fig. 5.f).

\subsection{Preliminary comparison of approaches for phenotyping applications}

In Fig. 7, we plot the RMSE of $C_{a b}$, LAI and CCC estimations per cultivar and per year as obtained using VIs and PROSAIL in the best configurations (see Fig. 4, Fig. 5 and Fig. 6). As observed in Fig. 7.a, VIs show less varying $C_{a b}$ estimation performances across the fourteen cultivars than PROSAIL inversion ( $\sigma=1.34 \mu \mathrm{g} / \mathrm{cm}^{2}$ for VIs and $\sigma=2.30 \mu \mathrm{g} / \mathrm{cm}^{2}$ for model inversion). Both remote-sensing methods, however, lead to similarly varying performances for LAI and CCC, with $\sigma$ being close to $0.065 \mathrm{~m}^{2} / \mathrm{m}^{2}$ and $0.035 \mathrm{~g} / \mathrm{m}^{2}$, respectively (Fig. $7 . \mathrm{b}-\mathrm{c}$ ).

As shown in Fig. 7.d-f, PROSAIL inversion shows remarkably stable performances across years for LAI $\left(\sigma \leq 0.01 \mathrm{~m}^{2} / \mathrm{m}^{2}\right), \operatorname{CCC}\left(\sigma=0.02 \mathrm{~g} / \mathrm{m}^{2}\right)$ and, to a lesser extent, $\mathrm{C}_{\mathrm{ab}}\left(\sigma=1.65 \mu \mathrm{g} / \mathrm{cm}^{2}\right)$. VIs also show stable performances for LAI $\left(\sigma=0.01 \mathrm{~m}^{2} / \mathrm{m}^{2}\right)$. However, the VI performances presented in Fig. 7.d and Fig. 7.f show that applying a statistical model calibrated either from 2015 data to 2016 data or from 2016 data to 2015 data results in more variable $C_{a b}\left(\sigma=3.03 \mu \mathrm{g} / \mathrm{cm}^{2}\right)$ and CCC $\left(\sigma=0.06 \mathrm{~g} / \mathrm{m}^{2}\right)$ estimation accuracies as compared to PROSAIL inversion. 
While, in Sections 3.2 and 3.3, VIs appear to provide more accurate $C_{a b}$, LAI and CCC retrievals than PROSAIL inversion, Fig. 7.d-f show that model inversion may, however, get closer to (e.g., for LAI) or even outperform (e.g., for $\mathrm{C}_{\mathrm{ab}}$ ) VIs when $\mathrm{VI}$ performances are estimated using two independent calibration and test data sets (instead of leave-one-out cross-validation). In the case of $C_{a b}$, the VI RMSE obtained with the 2016 model is even nearly twice as high as the RMSE obtained with PROSAIL inversion or the two-year model.
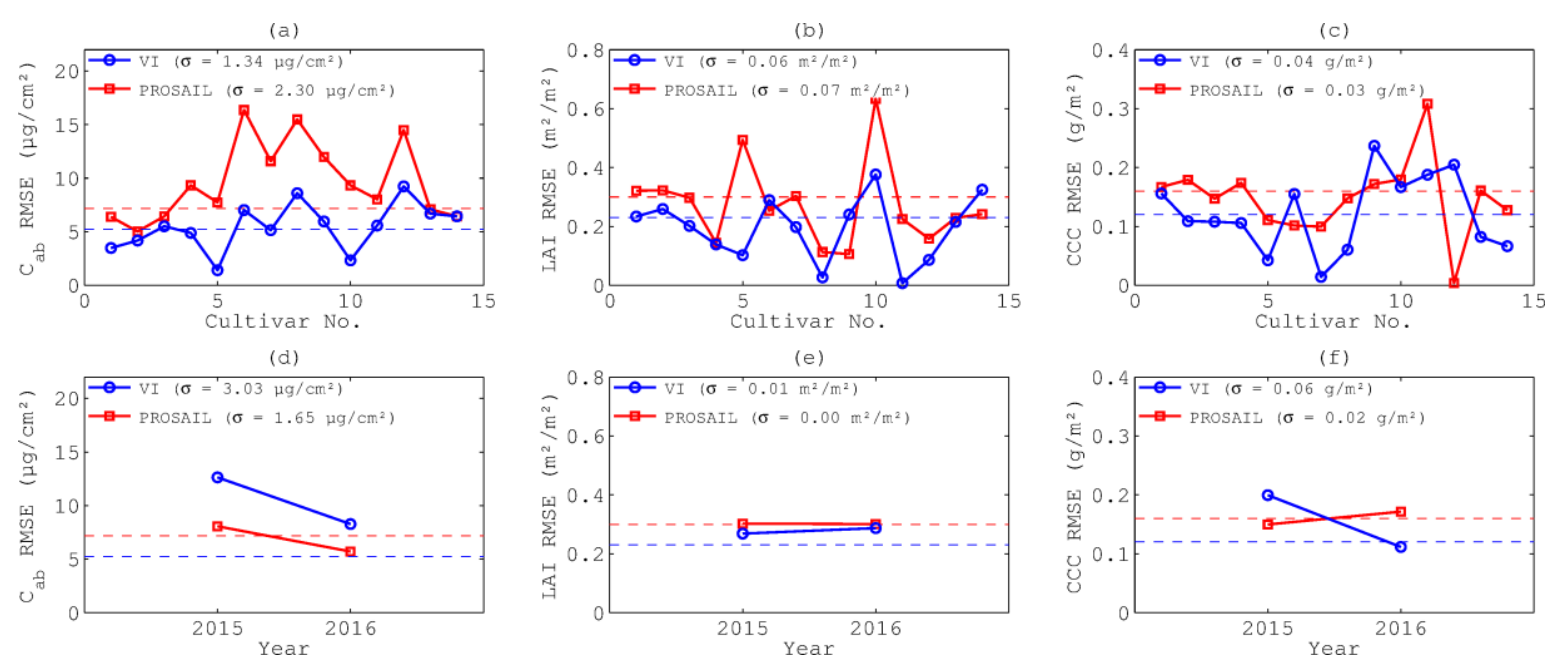

Figure 7: $\mathrm{C}_{\mathrm{ab}}$, LAl and CCC estimation performances obtained for each cultivar (a-c) and year (d-f) using VIs and PROSAIL inversion in the best configurations. For each parameter and method, $\sigma$ is the RMSE weighted standard deviation for which the numbers of samples per cultivar or per year were used as weights. Dashed lines represent the best overall RMSE as provided in previous sections.

\section{Discussion}

Especially due to the variable proportion of soil that is seen by the sensor, nadir observations are found to be mainly sensitive to structural sugar beet plant traits while off-nadir observations are found to be more sensitive to leaf biochemistry. This is in agreement with observations made for wheat (Comar et al., 2012) and cotton crops (Dorigo 2012). At nadir, the potentials of MCARI[705,750] and MCARI /OSAVI $[705,750]$ as accurate and linear predictors of LAl agree well with the results of Wu et al. (2008) obtained with PROSAIL-simulated canopies. These two VIs also strongly correlate with LAI 
and $\mathrm{CCC}$ in the forward direction $\left(+50^{\circ}\right)$, where shadows are increased as compared to homogeneous canopies because of high vegetation clumping. These observations likely demonstrate the robustness of MCARI[705,750] and MCARI/OSAVI[705,750] against canopy structure heterogeneity and shaded areas. In the backward direction $\left(-50^{\circ}\right)$, where the shadows are minimized and the soil influence is low, sugar beet canopies tend towards homogeneous and dense canopies. The better correlations obtained between chlorophyll VIs and $\mathrm{C}_{\mathrm{ab}}$ as compared with other viewing configurations are likely to be due to the high proportion of fully illuminated vegetated areas. Even if $m N D_{\text {blue }}$ was initially developed to estimate $C_{a b}$ from millimeter- to centimeter-scale imagery from which vegetation pixels could be extracted, these results show that it can also provide strong correlations at coarser spatial resolutions if the soil influence remains reasonable (e.g., in the case of dark loamy soil and/or off-nadir viewing). Unlike the other VIs tested, $m N D_{\text {blue }}$ appears to be poorly correlated with LAI and therefore CCC. As emphasized by Jay et al. (2017), this insensitivity to LAl variations is of tremendous importance as it tends to indicate that any correlation observed between $m N D_{\text {blue }}$ and $\mathrm{C}_{\mathrm{ab}}$ could not be caused by a correlation between LAI and $\mathrm{C}_{\mathrm{ab}}$. Moreover, the generally high correlations obtained both for $\mathrm{C}_{\mathrm{ab}}$ and for $\mathrm{LAl}$ at $-50^{\circ}$ makes this sun-sensor geometry the most appropriate to remotely sense the canopy chlorophyll content. The potentials of $C I_{\text {green }}, C I_{\text {red-edge }}$ and MTCI are in agreement with previous studies conducted with nadir observations and different canopy structures (Clevers and Gitelson 2013; Clevers and Kooistra 2012; Schlemmer et al. 2013). Ultimately, as mentioned in Section 2.4.1, the lower sensitivity of NDVI to $\mathrm{C}_{\mathrm{ab}}$ and LAI emphasizes the necessity of using spectral bands that are appropriate for the study case, especially in regard to canopy density and leaf biochemistry. It is worth noting that these wavebands could also be optimized for a given situation following the procedure implemented by Clevers and Gitelson (2013), Gitelson et al. (2003, 2006), and Schlemmer et al. (2013). 
Unlike $\mathrm{C}_{\mathrm{ab}}$ and LAI (and therefore CCC) whose variations are directly captured by the selected VIs, the nitrogen content poorly affects the measured canopy reflectance because nitrogen absorption features (that are located in the SWIR domain) tend to be negligible as compared with those of water (Curran 1989; Jacquemoud et al. 1996), the water being present both in the atmosphere and in the leaves. Importantly, this is even more critical for sugar beet since leaves contain a lot of water as compared with other species (see $C_{w}$ measurements in Table 2). For sugar beet crops, nitrogen quantities can therefore mainly be retrieved indirectly through their correlation with chlorophyll quantities and LAI. The results presented in Table 6 can thus be discussed using the relationships presented in Fig. 3 and Table 5. For leaf-level nitrogen quantities, the poor correlation between $\% \mathrm{~N}_{\text {leaf }}$ and $C_{a b}$ (Fig. 3.a) together with the difficulty in accurately estimating $C_{a b}$ from canopy reflectance (Table 5) result in poor correlations between VIs and $\% \mathrm{~N}_{\text {leaf. }}$. These results are similar to those obtained by Li et al. (2016), who also found that, for litchi orchards, $\% \mathrm{~N}_{\text {leaf }}$ could not be accurately predicted all along the growing season. However, the good correlations between $\mathrm{Vls}$ and $\% \mathrm{~N}_{\text {leaf }}$ obtained by $\mathrm{He}$, Song, et al. (2016) and He, Zhang, et al. (2016) in the case of winter wheat canopies show that estimation of leaf nitrogen concentration from remote sensing is a complex problem whose solution (if any) cannot be generalized to every plant species. The low correlations observed between VIs and $\% \mathrm{~N}_{\text {leaf }}$ are actually partly due to the use of a mass-based unit to express the leaf nitrogen content, since the use of an area-based unit results in increased correlations both between VIs and $C_{n}$, and between $C_{n}$ and $C_{a b}$. Variations in leaf thickness are indeed taken into account in mass-based quantities while they are not in area-based quantities: such variations are likely to introduce unexpected variations in canopy reflectance that can hardly be detected from remote sensing. These correlations are, however, still low to ensure an accurate retrieval of nitrogen content in sugar beet crops. The leaf-level relationship between chlorophyll and nitrogen contents actually depends on development stages (as mentioned by Baret et al. (2007) and Schlemmer et al. (2013) for wheat and maize crops, resp.), soil and weather conditions or even years as observed with cross and circle symbols in Fig. 3.a-b. Alternatively, scaling up $C_{n}$ and $C_{a b}$ to the canopy level makes it possible to take into account variations 
in nitrogen dilution within the foliage (Baret et al. 2007; Fitzgerald et al. 2010), and to reach a significantly stronger correlation between CNC and CCC (Fig. 3.c). Consequently, the strong linear relationships between VIs and CCC (Table 5) leads to the strong correlations between VIs and CNC presented in Table 6. Finally, this study suggests that the accurate $\mathrm{CNC}$ retrieval is mainly due to the VI abilities in retrieving LAI and to the strong correlation between LAI and biomass (Fig. 3.d). This hypothesis is supported by the results obtained using $C I_{\text {green }}$ in the $-50^{\circ}$ configuration and $\operatorname{MCARI}[705,750]$ in the $+50^{\circ}$ configuration. If both VIs obtain the same correlation with CCC $(r=$ 0.95), $C I_{\text {green }}$ correlates better with $C_{a b}(r=0.71$ against $r=0.58$ for $M C A R I[705,750])$, while MCARI $[705,750]$ correlates better with LAI $\left(r=0.93\right.$ against $r=0.86$ for $\left.C I_{\text {green }}\right)$. The better correlation with CNC obtained using MCARI[705,750] ( $r=0.93$ against $r=0.88$ for $\left.C I_{\text {green }}\right)$ therefore tends to demonstrate that the accuracy of CNC retrieval primarily depends on that of LAI retrieval and LAI/biomass correlation.

Overall, the results obtained using PROSAIL inversion confirm those obtained with VIs, i.e., the estimation accuracy depends on viewing configuration. Similarly to $\mathrm{Vls}, \mathrm{C}_{\mathrm{ab}}$ and $\mathrm{CCC}$ are retrieved more accurately in the backward scattering direction, while LAl is better estimated from nadir viewing. Fig. 4, Fig. 5 and Fig. 6 tend to indicate that PROSAIL inversion provides slightly poorer overall Cab, LAI and CCC estimation performances than VIs, the RMSE increasing by about $30 \%$ for LAI and CCC, and by $45 \%$ for $\mathrm{C}_{\mathrm{ab}}$. This is partly due to the fact that the SAIL model has been designed for spatially homogeneous media and thus does not perfectly describe the reflectance anisotropy of rowstructured sugar beet canopies (Zhao et al., 2010). Such anisotropy mismodeling may explain (1) why the use of multiple-view measurements does not necessarily improve the retrievals of $C_{a b}$, LAI and CCC, and (2) the compensations occurring between $C_{a b}$ and LAI (i.e., $C_{a b}$ underestimation compensates for LAl overestimation). These compensations are reduced when constraining the LUTs based on prior knowledge on $\mathrm{C}_{\mathrm{ab}}$ and LAl distributions, thus leading to better estimation performances for these two 
parameters (Fig. 6). However, constraining the LUT in such way has no significant effect on CCC retrieval, since the latter quantity is here defined as the product $L A I \times C_{a b}$ (i.e., $C_{a b}$ underestimation and LAl overestimation cancel each other out in the case of CCC estimation).

A solution to further improve the performances of PROSAIL inversion may be to use canopy spectral measurements acquired at a greater distance from sugar beet canopies. The inclusion of several crops rows within the sensor field-of-view is expected to smooth the spatial heterogeneity, thus improving the model accuracy and the retrieval performances. Alternatively, more complex models could be used to represent the anisotropy of sugar beet canopy reflectance (Huemmrich, 2001; Zhao et al., 2010), but this increase in complexity makes the inversion more challenging (if not impossible) without sufficient prior knowledge on canopy structure (e.g., plant height, row spacing, row width, etc). In a phenotyping context where thousands of unknown cultivars have to be addressed, the use of such complex models may thus be difficult without ancillary measurements, e.g., provided by stereovisionor photogrammetry-based methods (Jay et al., 2015).

The preliminary study presented in Fig. 6 tends to show that VIs provide both accurate and robust $C_{a b}$, LAI and CCC estimation performances when tested across the fourteen sugar beet cultivars introduced in Section 2. This means that the differences between considered cultivars (e.g., in plant architecture) are not sufficient to significantly affect the VI performances. VIs must, however, be used with great care as illustrated, e.g., by the poor $C_{a b}$ estimation results obtained using 2015 and 2016 models (Fig. 6.d). Although these results may indicate a possible year effect, closer inspection of 2015 and $2016 C_{a b}$ distributions (see crosses and circles in Fig. 4.a) rather shows that these poor performances are due to differences in $C_{a b}$ range: $C_{a b}$ indeed ranged between 37.3 and $58.4 \mu \mathrm{g} / \mathrm{cm}^{2}$ in 2015 , and between 27.1 and $42.6 \mu \mathrm{g} / \mathrm{cm}^{2}$ in 2016 . This emphasizes the necessity of including enough samples for calibration so that the statistical model can be accurate over the whole range of possible values. 
On the other hand, the performances obtained with PROSAIL inversion do not depend on a calibration set, and are generally at least as much stable as VI performances across different cultivars and years (note, however, that model inversion usually requires additional knowledge on the distributions of targeted parameters to achieve desirable performances). PROSAIL inversion only shows significantly more variable performances across different cultivars for $C_{a b}$, which may be due to the strong sensitivity of $m N D_{\text {blue }}$ to $\mathrm{C}_{\mathrm{ab}}$ variations and to the PROSAIL difficulties in effectively decoupling LAI and Cab.

These results thus suggest that, providing that enough samples are used to calibrate the VI statistical model,

- VIs offer slightly more accurate performances than PROSAIL inversion. These, however, need to be quantified more rigorously using two independent calibration and test data sets of sufficient size, since the leave-one-out cross-validation process used in this paper to estimate the RMSE is known to provide slightly over-optimistic performances.

- Both remote-sensing methods offer similar robustness properties for LAI and CCC phenotyping in sugar beet crops. In the case of $C_{a b}$, VIs tend to offer less variable estimation performances than PROSAIL inversion across the fourteen tested cultivars, but more samples are also required to draw definitive conclusions.

\section{Conclusions and perspectives}

This study investigates the potential of ground-based multi-angular optical remote sensing to retrieve structural (LAI) and biochemical (chlorophyll and nitrogen contents) sugar beet plant traits in a phenotyping context. A statistically-based method based on vegetation indices and a physically-based method based on PROSAIL inversion are tested and compared. For both approaches, we emphasize the importance of choosing an appropriate viewing configuration that maximizes the reflectance sensitivity to the targeted parameter. Nadir and oblique measurements are indeed more sensitive to canopy structure and leaf biochemistry, respectively, especially due to the variable proportions of soil 
and vegetation that are seen by the sensor. Both VIs and PROSAIL inversion are promising to phenotype canopy-level quantities, i.e., LAI and CCC, in sugar beet crops (RMSE $\leq 10 \%$ ). In addition, VIs enable an accurate retrieval of CNC (RMSE $=10 \%)$. Estimating leaf-level quantities, i.e., $\mathrm{C}_{\mathrm{ab}}$, $\% \mathrm{~N}_{\text {leaf }}$ and $\mathrm{C}_{\mathrm{n}}$, is more difficult, even if the use of $m N D_{\text {blue }}$ based on measurements acquired in the backward scattering direction shows interesting results, the RMSE ranging from $17 \%$ for $\mathrm{C}_{\mathrm{ab}}$ to $22 \%$ for $\% \mathrm{~N}_{\text {leaf }}$. Although VI-based methods generally perform slightly better than PROSAIL inversion over the fourteen tested cultivars, an important question is whether the use of such statistically-based methods is fully relevant for phenotyping applications. The first results indicate that VIs may offer both accurate and robust estimation performances, providing that enough samples covering the whole range of possible values are included in the calibration set. However, more data, including cultivars with a potentially strongly different plant architecture or chlorophyll/nitrogen ratio, are still necessary to draw definitive conclusions. Indeed, given the close performances obtained with both remotesensing methods, PROSAIL inversion may perform better than VIs if the level of heterogeneity within all the cultivars to be phenotyped (i.e., in practice, thousands of cultivars) is very high.

Our future works will therefore be dedicated to testing these methods over a larger number of cultivars (or even other similar plant species) in order to further assess their accuracy and robustness. The potential of UAV-embedded multispectral cameras will also be investigated in the perspective of highthroughput phenotyping. As mentioned earlier, the observation of sugar beet canopies at a greater distance is likely to improve the PROSAIL inversion performances, which means that both methods should also be compared for such coarser spatial resolutions. Interestingly, digital cameras could also be embedded on UAVs so as to derive preliminary estimates of crop structure attributes (e.g., height, row spacing, row volume, etc) using stereovision- or photogrammetry-based methods. These estimates could then be included as known values during PROSAIL inversion in order to reduce the problem ill-posedness and increase the estimation accuracy. Note that PROSAIL inversion could also potentially be improved by using another inversion method (e.g., artificial neural networks), as this may have a substantial effect on the retrieval performances (Vohland et al., 2010). 
Ultimately, further work is required to optimize the sun-sensor geometry with respect to the row orientation, especially in terms of azimuth angle. Instead of positioning the sensor as a function of sun position, it would be interesting to position it as a function of row orientation. In particular, an improved sensitivity to leaf biochemistry could be expected when positioning the sensor perpendicularly to the row, this direction maximizing the observed amount of leaves for rowstructured canopies (Baret et al. 2010; Comar et al. 2012).

\section{Acknowledgments}

This study was funded by the French Ministry of Agriculture, Agrifood, and Forestry (PHENOBET project), and by the French National Research Agency, within the program "Investissements d'avenir" with the reference ANR-11-BTBR-0007 (AKER project). The authors want to thank warmly Stéphanie Heno, Ghislain Malatesta and Daniel Moura for their valuable assistance in the field experiments, Dan Dutartre and Frédéric Baret for their help in the LUT implementation, and the anonymous reviewers for their valuable comments and suggestions.

\section{References}

Bacour, C., Jacquemoud, S., Tourbier, Y., Dechambre, M., Frangi, J.-P., 2002. Design and analysis of numerical experiments to compare four canopy reflectance models. Remote Sens. Environ. 79, 72-83. doi:10.1016/S0034-4257(01)00240-1

Baret, F., Buis, S., 2008. Estimating canopy characteristics from remote sensing observations: review of methods and associated problems, in: Liang, S. (Ed.), Advances in Land Remote Sensing: System, Modeling, Inversion and Application. pp. 173-201. doi:10.1007/978-1-4020-6450-0_7

Baret, F., de Solan, B., Lopez-Lozano, R., Ma, K., Weiss, M., 2010. GAl estimates of row crops from downward looking digital photos taken perpendicular to rows at $57.5^{\circ}$ zenith angle: Theoretical considerations based on 3D architecture models and application to wheat crops. Agric. For. 
Meteorol. 150, 1393-1401. doi:10.1016/j.agrformet.2010.04.011

Baret, F., Houlès, V., Guérif, M., 2007. Quantification of plant stress using remote sensing observations and crop models: The case of nitrogen management. J. Exp. Bot. 58, 869-880. doi:10.1093/jxb/erl231

Baret, F., Jacquemoud, S., Guyot, G., Leprieur, C., 1992. Modeled analysis of the biophysical nature of spectral shifts and comparison with information content of broad bands. Remote Sens. Environ. $41,133-142$.

Blackburn, G.A., 2007. Hyperspectral remote sensing of plant pigments. J. Exp. Bot. 58, 855-867. doi:10.1093/jxb/erl123

Cerovic, Z.G., Masdoumier, G., Ghozlen, N. Ben, Latouche, G., 2012. A new optical leaf-clip meter for simultaneous non-destructive assessment of leaf chlorophyll and epidermal flavonoids. Physiol. Plant. 146, 251-260. doi:10.1111/j.1399-3054.2012.01639.x

Cho, M.A., Skidmore, A.K., 2006. A new technique for extracting the red edge position from hyperspectral data: The linear extrapolation method. Remote Sens. Environ. 101, 181-193.

Clevers, J., Kooistra, L., 2012. Using Hyperspectral Remote Sensing Data for Retrieving Canopy Chlorophyll and Nitrogen Content. leee J. Sel. Top. Appl. Earth Obs. Remote Sens. 5, 574-583. doi:10.1109/JSTARS.2011.2176468

Clevers, J.G.P.W., Gitelson, A.A., 2013. Remote estimation of crop and grass chlorophyll and nitrogen content using red-edge bands on sentinel-2 and-3. Int. J. Appl. Earth Obs. Geoinf. 23, 344-351. doi:10.1016/j.jag.2012.10.008

Colombo, R., Meroni, M., Marchesi, a., Busetto, L., Rossini, M., Giardino, C., Panigada, C., 2008. Estimation of leaf and canopy water content in poplar plantations by means of hyperspectral indices and inverse modeling. Remote Sens. Environ. 112, 1820-1834. doi:10.1016/j.rse.2007.09.005 
Comar, A., Burger, P., de Solan, B., Baret, F., Daumard, F., Hanocq, J.-F., 2012. A semi-automatic system for high throughput phenotyping wheat cultivars in-field conditions: description and first results. Funct. Plant Biol. 39, 914-924. doi:10.1071/FP12065

Combal, B., Baret, F., Weiss, M., Trubuil, A., Macé, D., Pragnère, A., Myneni, R., Knyazikhin, Y., Wang, L., 2003. Retrieval of canopy biophysical variables from bidirectional reflectance: Using prior information to solve the ill-posed inverse problem. Remote Sens. Environ. 84, 1-15. doi:10.1016/S0034-4257(02)00035-4

Curran, P.J., 1989. Remote sensing of foliar chemistry. Remote Sens. Environ. 30, 271-278.

Darvishzadeh, R., Atzberger, C., Skidmore, A., Schlerf, M., 2011. Mapping grassland leaf area index with airborne hyperspectral imagery: A comparison study of statistical approaches and inversion of radiative transfer models. ISPRS J. Photogramm. Remote Sens. 66, 894-906. doi:10.1016/j.isprsjprs.2011.09.013

Dash, J., Curran, P.J., 2004. The MERIS terrestrial chlorophyll index. Int. J. Remote Sens. 25, 54035413. doi:10.1080/0143116042000274015

Daughtry, C.S.., Walthall, C.., Kim, M.., de Colstoun, E.B., McMurtrey, J.., 2000. Estimating Corn Leaf Chlorophyll Concentration from Leaf and Canopy Reflectance. Remote Sens. Environ. 74, 229239. doi:10.1016/\$0034-4257(00)00113-9

Dorigo, W. a., 2012. Improving the robustness of cotton status characterisation by radiative transfer model inversion of multi-angular CHRIS/PROBA data. IEEE J. Sel. Top. Appl. Earth Obs. Remote Sens. 5, 18-29. doi:10.1109/JSTARS.2011.2171181

Dorigo, W. a., Zurita-Milla, R., de Wit, a. J.W., Brazile, J., Singh, R., Schaepman, M.E., 2007. A review on reflective remote sensing and data assimilation techniques for enhanced agroecosystem modeling. Int. J. Appl. Earth Obs. Geoinf. 9, 165-193. doi:10.1016/j.jag.2006.05.003 
estimate leaf area index of maize, potato, and sunflower fields from unmanned aerial vehicle hyperspectral data. Int. J. Appl. Earth Obs. Geoinf. 26, 12-20. doi:10.1016/j.jag.2013.05.007

Dumas, J.B.A., 1831. Procedes de l'analyse organique. Ann. Chim. Phys 47, 198-205.

Feret, J.-B., François, C., Asner, G.P., Gitelson, A. a., Martin, R.E., Bidel, L.P.R., Ustin, S.L., le Maire, G., Jacquemoud, S., 2008. PROSPECT-4 and 5: Advances in the leaf optical properties model separating photosynthetic pigments. Remote Sens. Environ. 112, 3030-3043. doi:10.1016/j.rse.2008.02.012

Fitzgerald, G., Rodriguez, D., O'Leary, G., 2010. Measuring and predicting canopy nitrogen nutrition in wheat using a spectral index-The canopy chlorophyll content index (CCCI). F. Crop. Res. 116, 318-324.

François, C., Ottlé, C., Olioso, A., Prévot, L., Bruguier, N., Ducros, Y., 2002. Conversion of 400-1100 nm vegetation albedo measurements into total shortwave broadband albedo using a canopy radiative transfer model. Agronomie 22, 611-618.

Furbank, R.T., Tester, M., 2011. Phenomics - technologies to relieve the phenotyping bottleneck. Trends Plant Sci. 16, 635-644. doi:10.1016/j.tplants.2011.09.005

Gitelson, A.A., Gritz, Y., Merzlyak, M.N., 2003. Relationships between leaf chlorophyll content and spectral reflectance and algorithms for non-destructive chlorophyll assessment in higher plant leaves. J. Plant Physiol. 160, 271-282. doi:10.1078/0176-1617-00887

Gitelson, A.A., Kaufman, Y.J., Merzlyak, M.N., 1996. Use of a green channel in remote sensing of global vegetation from EOS-MODIS. Remote Sens. Environ. 58, 289-298. doi:10.1016/S00344257(96)00072-7

Gitelson, A.A., Keydan, G.P., Merzlyak, M.N., 2006. Three-band model for noninvasive estimation of chlorophyll, carotenoids, and anthocyanin contents in higher plant leaves. Geophys. Res. Lett. 33, 1-6. doi:10.1029/2006GL026457 
Gitelson, A.A., Merzlyak, M.N., 1994. Spectral Reflectance Changes Associated with Autumn Senescence of Aesculus-hippocastanum L. and Acer-platanoides L. Leaves - Spectral Features and Relation to Chlorophyll Estimation. J. Plant Physiol. 143, 286-292. doi:10.1016/S0176$1617(11) 81633-0$

Gitelson, A.A., Vina, A., Ciganda, V., Rundquist, D.C., Arkebauer, T.J., 2005. Remote estimation of canopy chlorophyll content in crops. Geophys. Res. Lett. 32, 1-4. doi:10.1029/2005GL022688

Guyot, G., Baret, F., 1988. Utilisation de la haute resolution spectrale pour suivre l'etat des couverts vegetaux, in: Spectral Signatures of Objects in Remote Sensing. p. 279.

Haboudane, D., Miller, J.R., Pattey, E., Zarco-Tejada, P.J., Strachan, I.B., 2004. Hyperspectral vegetation indices and novel algorithms for predicting green LAI of crop canopies: Modeling and validation in the context of precision agriculture. Remote Sens. Environ. 90, 337-352.

He, L., Song, X., Feng, W., Guo, B.-B., Zhang, Y.-S., Wang, Y.-H., Wang, C.-Y., Guo, T.-C., $2016 a$. Improved remote sensing of leaf nitrogen concentration in winter wheat using multi-angular hyperspectral data. Remote Sens. Environ. 174, 122-133. doi:10.1016/j.rse.2015.12.007

He, L., Zhang, H.Y., Zhang, Y.S., Song, X., Feng, W., Kang, G.Z., Wang, C.Y., Guo, T.C., 2016b. Estimating canopy leaf nitrogen concentration in winter wheat based on multi-angular hyperspectral remote sensing. Eur. J. Agron. 73, 170-185. doi:10.1016/j.eja.2015.11.017

Hilker, T., Gitelson, A., Coops, N.C., Hall, F.G., Black, T.A., 2011. Tracking plant physiological properties from multi-angular tower-based remote sensing. Oecologia 165, 865-876.

Huemmrich, K.F., 2001. The GeoSail model: a simple addition to the SAIL model to describe discontinuous canopy reflectance. Remote Sens. Environ. 75, 423-431.

Inoue, Y., Sakaiya, E., Zhu, Y., Takahashi, W., 2012. Diagnostic mapping of canopy nitrogen content in rice based on hyperspectral measurements. Remote Sens. Environ. 126, 210-221. doi:10.1016/j.rse.2012.08.026 
Jacquemoud, S., Baret, F., 1990. PROSPECT: A model of leaf optical properties spectra. Remote Sens.

Environ. 34, 75-91. doi:10.1016/0034-4257(90)90100-Z

Jacquemoud, S., Baret, F., Andrieu, B., Danson, F.M., Jaggard, K., 1995. Extraction of Vegetation Biophysical Parameters by Inversion of the PROSPECT + SAIL Models on Sugar Beet Canopy Reflectance Data. Application to TM and AVIRIS Sensors. Remote Sens. Environ. 52, 163-172.

Jacquemoud, S., Ustin, S.L., Verdebout, J., Schmuck, G., Andreoli, G., Hosgood, B., 1996. Estimating leaf biochemistry using the PROSPECT leaf optical properties model. Remote Sens. Environ. 56, 194-202.

Jacquemoud, S., Verhoef, W., Baret, F., Bacour, C., Zarco-Tejada, P.J., Asner, G.P., François, C., Ustin, S.L., 2009. PROSPECT+SAIL models: A review of use for vegetation characterization. Remote Sens. Environ. 113, S56-S66. doi:10.1016/j.rse.2008.01.026

Jay, S., Bendoula, R., Hadoux, X., Féret, J.-B., Gorretta, N., 2016. A physically-based model for retrieving foliar biochemistry and leaf orientation using close-range imaging spectroscopy. Remote Sens. Environ. 177, 220-236. doi:http://dx.doi.org/10.1016/j.rse.2016.02.029

Jay, S., Gorretta, N., Morel, J., Maupas, F., Bendoula, R., Rabatel, G., Dutartre, D., Comar, A., Baret, F., 2017. Estimation of leaf chlorophyll content in sugar beet canopies using millimeter- to centimeter-scale reflectance imagery. Remote Sens. Environ. accepted.

Jay, S., Rabatel, G., Hadoux, X., Moura, D., Gorretta, N., 2015. In-field crop row phenotyping from 3D modeling performed using Structure from Motion. Comput. Electron. Agric. 110, 70-77. doi:10.1016/j.compag.2014.09.021

Kuusk, A., 1991. The hot spot effect in plant canopy reflectance, in: Photon-Vegetation Interactions. Springer, pp. 139-159.

Li, D., Wang, C., Liu, W., Peng, Z., Huang, S., Huang, J., Chen, S., 2016. Estimation of litchi (Litchi chinensis Sonn.) leaf nitrogen content at different growth stages using canopy reflectance 
spectra. Eur. J. Agron. 80, 182-194.

Loel, J., Kenter, C., Märländer, B., Hoffmann, C.M., 2014. Assessment of breeding progress in sugar beet by testing old and new varieties under greenhouse and field conditions. Eur. J. Agron. 52, 146-156. doi:10.1016/j.eja.2013.09.016

Milford, G.F.J., Pocock, T.O., Riley, J., Messem, A.B., 1985. An analysis of leaf growth in sugar beet. Ann. Appl. Biol. 106, 187-203. doi:10.1111/j.1744-7348.1985.tb03108.x

Montes, J.M., Melchinger, A.E., Reif, J.C., 2007. Novel throughput phenotyping platforms in plant genetic studies. Trends Plant Sci. 12, 433-436. doi:10.1016/j.tplants.2007.08.006

Nicodemus, F., Richmond, J., Hsia, J., 1977. Geometrical considerations and nomenclature for reflectance. Sci. Technol. 60, 1-52. doi:10.1109/LPT.2009.2020494

Rondeaux, G., Steven, M., Baret, F., 1996. Optimization of soil-adjusted vegetation indices. Remote Sens. Environ. 55, 95-107. doi:10.1016/0034-4257(95)00186-7

Rouse, J.W., Hass, R.H., Schell, J.A., Deering, D.W., 1973. Monitoring vegetation systems in the great plains with ERTS. Third Earth Resour. Technol. Satell. Symp. 1, 309-317. doi:citeulike-articleid:12009708

Schaepman-Strub, G., Schaepman, M.E., Painter, T.H., Dangel, S., Martonchik, J. V., 2006. Reflectance quantities in optical remote sensing-definitions and case studies. Remote Sens. Environ. 103, 27-42. doi:10.1016/j.rse.2006.03.002

Schlemmer, M., Gitelson, a., Schepers, J., Ferguson, R., Peng, Y., Shanahan, J., Rundquist, D., 2013. Remote estimation of nitrogen and chlorophyll contents in maize at leaf and canopy levels. Int. J. Appl. Earth Obs. Geoinf. 25, 47-54. doi:10.1016/j.jag.2013.04.003

Sims, D.A., Gamon, J.A., 2002. Relationships between leaf pigment content and spectral reflectance across a wide range of species, leaf structures and developmental stages. Remote Sens. 
Environ. 81, 337-354. doi:10.1016/S0034-4257(02)00010-X

Song, X., Xu, D., He, L., Feng, W., Wang, Y., Wang, Z., Coburn, C.A., Guo, T., 2016. Using multi-angle hyperspectral data to monitor canopy leaf nitrogen content of wheat. Precis. Agric. 17, 721736. doi:10.1007/s11119-016-9445-x

Thorp, K.R., Gore, M.A., Andrade-Sanchez, P., Carmo-Silva, A.E., Welch, S.M., White, J.W., French, A.N., 2015. Proximal hyperspectral sensing and data analysis approaches for field-based plant phenomics. Comput. Electron. Agric. 118, 225-236. doi:10.1016/j.compag.2015.09.005

Verger, A., Vigneau, N., Chéron, C., Gilliot, J.M., Comar, A., Baret, F., 2014. Green area index from an unmanned aerial system over wheat and rapeseed crops. Remote Sens. Environ. 152, 654-664. doi:10.1016/j.rse.2014.06.006

Verhoef, W., 1998. Theory of radiative transfer models applied in optical remote sensing of vegetation canopies. Wageningen Agricultural University.

Verhoef, W., 1985. Earth observation modeling based on layer scattering matrices. Remote Sens. Environ. 17, 165-178.

Verhoef, W., 1984. Light scattering by leaf layers with application to canopy reflectance modeling: The SAIL model. Remote Sens. Environ. 16, 125-141. doi:10.1016/0034-4257(84)90057-9

Verhoef, W., Jia, L., Xiao, Q., Su, Z., 2007. Unified optical-thermal four-stream radiative transfer theory for homogeneous vegetation canopies. Geosci. Remote Sensing, IEEE Trans. 45, 18081822.

Verrelst, J., Camps-Valls, G., Muñoz-Marí, J., Rivera, J.P., Veroustraete, F., Clevers, J.G.P.W., Moreno, J., 2015. Optical remote sensing and the retrieval of terrestrial vegetation bio-geophysical properties - A review. ISPRS J. Photogramm. Remote Sens. doi:10.1016/j.isprsjprs.2015.05.005 Vohland, M., Mader, S., Dorigo, W., 2010. Applying different inversion techniques to retrieve stand 
variables of summer barley with PROSPECT + SAIL. Int. J. Appl. Earth Obs. Geoinf. 12, 71-80. doi:10.1016/j.jag.2009.10.005

Werker, A.R., Jaggard, K.W., Allison, M.F., 1999. Modelling partitioning between structure and storage in sugar beet: Effects of drought and soil nitrogen. Plant Soil 207, 97-106. doi:10.1023/A:1004444128026

Widlowski, J.L., Pinty, B., Gobron, N., Verstraete, M.M., Diner, D.J., Davis, A.B., 2004. Canopy structure parameters derived from multi-angular remote sensing data for terrestrial carbon studies. Clim. Change 67, 403-415.

Wu, C., Niu, Z., Tang, Q., Huang, W., 2008. Estimating chlorophyll content from hyperspectral vegetation indices: Modeling and validation. Agric. For. Meteorol. 148, 1230-1241. doi:10.1016/j.agrformet.2008.03.005

Xu, X., Zhao, C., Wang, J., Zhang, J., Song, X., 2014. Using optimal combination method and in situ hyperspectral measurements to estimate leaf nitrogen concentration in barley. Precis. Agric. 15, $227-240$.

Yang, G., Zhao, C., Liu, Q., Huang, W., Wang, J., 2011. Inversion of a radiative transfer model for estimating forest LAI from multisource and multiangular optical remote sensing data. IEEE Trans. Geosci. Remote Sens. 49, 988-1000.

Zarco-Tejada, P.., Miller, J.., Morales, A., Berjón, A., Agüera, J., 2004. Hyperspectral indices and model simulation for chlorophyll estimation in open-canopy tree crops. Remote Sens. Environ. 90, 463-476. doi:10.1016/j.rse.2004.01.017

Zhao, F., Gu, X., Verhoef, W., Wang, Q., Yu, T., Liu, Q., Huang, H., Qin, W., Chen, L., Zhao, H., 2010. A spectral directional reflectance model of row crops. Remote Sens. Environ. 114, 265-285. 